\title{
The synergetic effects of surface texturing and MoDDP additive applied to ball-on-disk friction subject to both flooded and
} starved lubrication conditions

\author{
Linqing Bai ${ }^{1}$, Yonggang Meng ${ }^{1 *}$, Zulfiqar Ahmad Khan ${ }^{2}$, Varian Zhang ${ }^{3}$ \\ ${ }^{1}$ State Key Laboratory of Tribology, Tsinghua University, Beijing, 100084, China \\ ${ }^{2}$ Department of Design and Engineering, Nanocorr, Energy and Modelling (NCEM), \\ Bournemouth University, Dorset, BH12 5BB, UK \\ ${ }^{3}$ Shell (Shanghai) Research Limited, Building 4, 4560 Jinke Road, Pudong New \\ District, Shanghai, 201210, China
}

\begin{abstract}
This paper reports a novel work on the synergetic effects of microscale surface texturing and lubricant friction modifier additive of molybdenum dialkyldithiophosphate (MoDDP) subject to both flooded and starved lubrication conditions. The experiments were performed on reciprocating ball-on-disk friction in GTL8 base oil with and without MoDDP. In the flooded lubrication condition, the test results demonstrated that the presence of the MoDDP additive contributed to lower friction coefficients, and also more pronounced effect of surface textures on friction than in the case of the bare base oil. In the starved lubrication experiments, textured and texture-free surfaces in the oils with and without MoDDP additive were tested until an abrupt rising of friction coefficient was detected. The results showed that the magnitude of friction coefficient before terminating each test was the almost same for various tests, while the endurance time in different test conditions was significantly different. The textured surface exhibited longer endurance time than the texture-free surface, especially when the MoDDP additive was used. The mechanism of the synergetic effects of surface textures and MoDDP additive has been discussed based on the experimental observations in the following sections. This study provides a new idea for the application of surface texture in boundary lubrication when lubricant additive is contained in the lubricating oils.
\end{abstract}

Key words: surface textures, friction modifier MoDDP, boundary lubrication, starved oil lubrication 


\section{Introduction}

Boundary lubrication is widely observed in almost all mechanical operations [1]. Friction mainly comes from the resistance during boundary lubrication to break solid-to-solid asperity junctions, and as an accompanying event of the junction breakdown, harmful adhesive wear particles are usually generated. Hence friction and wear reduction could not be achieved unless the contact intensity of the asperities is relieved and the strength of asperity junctions is weakened. Formation of adsorbed organic films or soft reaction products by rubbing, often referred to as tribofilms, on metallic surfaces with the aid of lubricant additives, such as friction modifiers, is one of the technologies available to reduce boundary friction $[2,3]$.

Molybdenum dialkyldithiophosphate (MoDDP) is a typical friction modifier which is often used in many industrial and automotive applications to reduce frictional energy losses [4]. A lot of experimental results have shown that it can reduce friction and increase durability of metal surfaces by forming a tribofilm [5-11]. Previous results have demonstrated that MoDDP reaction films could produce low friction coefficient (less than 0.05) after a few running cycles [8]. Anti-wear performance of MoDDP additive with various concentrations has also been investigated previously [9]. At low concentrations the MoDDP additive did not improve the anti-wear properties of commercial grade engine oils, but a relatively higher concentration of MoDDP could potentially improve the anti-wear properties of commercial engine oils. Meanwhile, the mechanisms of MoDDP friction modifier have attracted significant attention over the past few decades. It is widely assumed that $\mathrm{MoS}_{2}$ sheets which are formed by tribochemical reactions between the sliding surfaces, leading to low friction [4].

In recent years, another attractive technology, known as surface texturing, for reducing friction and wear has emerged and been gradually applied to many machine elements, including mechanical seals, thrust and journal bearings and piston rings [12-16]. The effect of surface textures on tribology is different from friction modifiers, anti-wear and extreme pressure lubricant additives which protect friction surfaces from severe wear through tribochemical reaction. Surface texturing reforms surface topography by constructing regular distributions of dimples, grooves or bumps on a machined surface at micro and/or nano scales by micro/nanofabrication processes [17-21]. The most commonly used texture processing methods are laser ablation, photochemical machining, electric discharge machining. The introduction of surface textures could influence many aspects of interface phenomena, such as real contact area, lubricating oil, pressure and wear debris distributions in the contact zone. Consequently, this may result in impacts on the formation, maintaining and removal of boundary film. However, to date, most previous studies of surface texturing effects focused on the hydrodynamic lubrication regime where no wear occurs and boundary films have little influence on friction. In literature, there are a few reports of surface 
texturing effect on boundary lubrication state [22-27]. The tribological effects and key parameters of textured surfaces in sliding contact with boundary lubrication has been discussed in these published results. However, none of the previous studies explored whether and how surface texturing alters the boundary lubrication performance of MoDDP friction modifier.

Microscale dimples and grooves act as lubricant oil reservoirs are usually beneficial in terms of reducing or even preventing interfacial scuffing and seizure during start-stop conditions when oil supplies are low which in turn presents starved lubrication regimes. Some researches have demonstrated the oil film thickness was bigger when passing through micro dents than across smooth surface during starved elastohydrodynamic lubrication (EHL) contacts [28,29]. Until now, it is not clear what role the MoDDP additive can play under starved boundary lubrication in the presence of surface textures.

In this study, two types of most commonly used microscale textures, circular dimples and line grooves, were tested in both flooded and starved boundary lubrication conditions. Gas to liquid (GTL) with and without MoDDP additive were used as the lubricating oils. The purpose of this work is to provide some insights into the application of surface textures in boundary lubrication of MoDDP contained oils. The authors believed that this is the first report in terms of detailed investigation of the synergetic effects between microscale surface texturing and lubricant additive MoDDP.

\section{Experimental details}

\subsection{Test rig}

Tribological experiments were performed on a reciprocating tribometer UMT-3 (Center for Tribology, Inc.) by using a ball-on-plate module as shown in Fig.1. The dimensions and properties of the ball and plate are shown in Fig.1 and Table 1. During the tests, the ball was stationary, while the plate slid forth and back. The operation conditions are shown in Table 2. The maximum Hertz contact pressure and contact radius are $2.569 \mathrm{GPa}$ and $0.167 \mathrm{~mm}$ respectively under the operation conditions. 


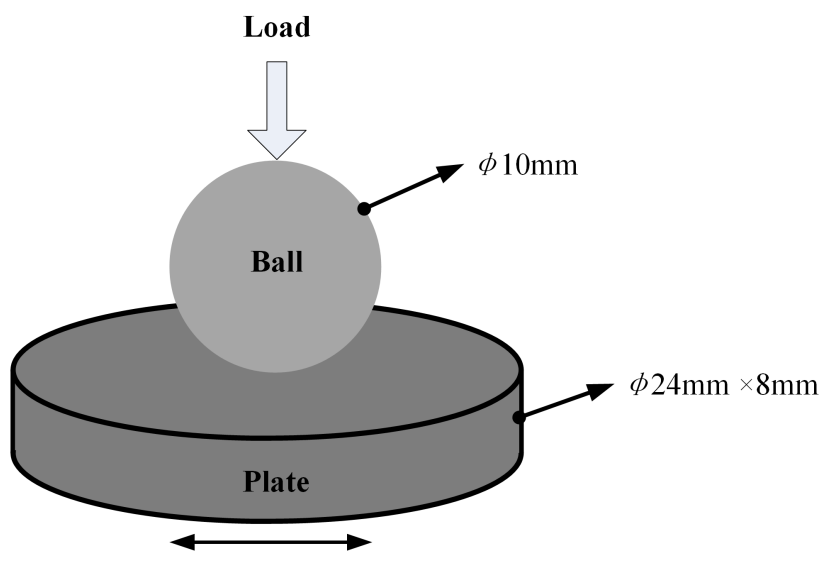

Fig.1 Schematic of test rig

Table 1 Sample properties

\begin{tabular}{ccccc}
\hline & Material & Hardness / HV & Elastic-modulus & Poisson's ratio \\
\hline Ball & $52100 \mathrm{steel}$ & $826(@ 300 \mathrm{~g}, 10 \mathrm{~s})$ & $210 \mathrm{GPa}$ & 0.3 \\
Plate & $52100 \mathrm{steel}$ & $719(@ 300 \mathrm{~g}, 10 \mathrm{~s})$ & $210 \mathrm{GPa}$ & 0.3 \\
\hline
\end{tabular}

Table 2 Test conditions

\begin{tabular}{cccc}
\hline Load & Stroke & Sliding frequency & Temperature \\
\hline $150 \mathrm{~N}$ & $5 \mathrm{~mm}$ & $5 \mathrm{~Hz}$ & $20^{\circ} \mathrm{C}$ \\
\hline
\end{tabular}

\subsection{Test programme}

Before the testing, both the balls and plates were ultrasonically conditioned in a petroleum ether bath, then acetone bath and alcohol bath for 5 minutes respectively. The balls and plates were dried with compressed nitrogen after conditioning. At the beginning of the test, a few droplets of lubricant were introduced between the ball and the plate to ensure that the oil supply between the contacting surfaces was maintained. In order to study the friction performance under both flooded and starved lubrication conditions, two different oil supply methods were used in this experiment. Before friction test, $500 \mu \mathrm{L}$ lubricant was introduced between the ball and the plate to ensure sufficient oil supply between the contacting surfaces for the flooded lubrication conditions. While, for the starved lubrication, only $1.5 \mu \mathrm{L}$ lubricant was supplied onto the plate then the plate was smeared on the plate surface carefully by a rubber bar to make sure that the plate was coated uniformly with a thin layer of lubricant (as shown in Fig.2). Fig.3 (a) and Fig.3 (b) show the schematics of a flooded and starved lubrication condition, and the contact zone is also presented in Fig.3 (c). Each test were repeated for three and two times for the flooded and starved lubrication respectively. The test programme are shown in Table 3. 


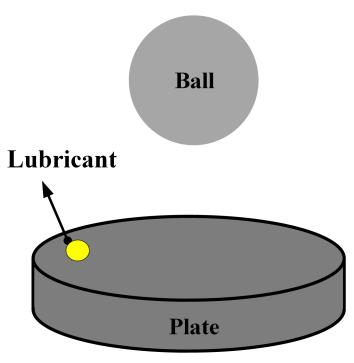

(a)

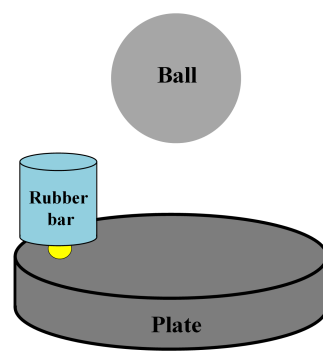

(b)

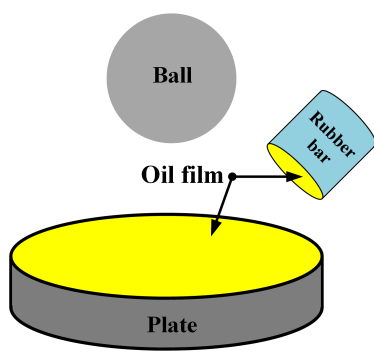

(c)

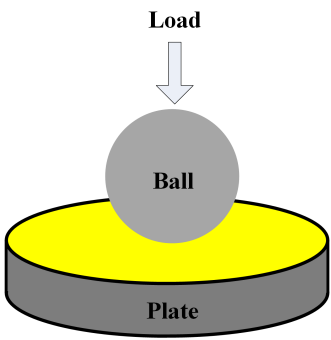

(d)

Fig. 2 Lubricant supply under starved lubrication

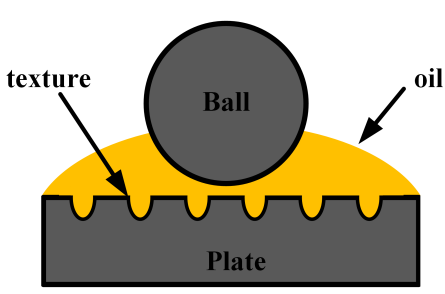

(a) flooded lubrication

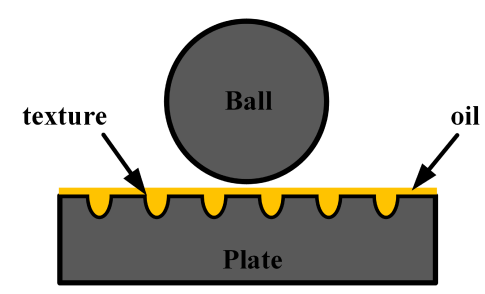

(b) starved lubrication

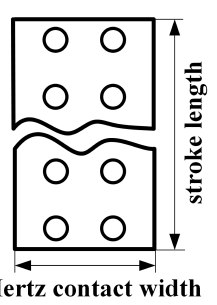

(c) contact region

Fig.3 Schematic diagram of lubrication conditions

Table 3 Test programmes

\begin{tabular}{|c|c|c|c|c|c|c|c|}
\hline $\begin{array}{l}\text { Test } \\
\text { No. }\end{array}$ & $\begin{array}{c}\text { Lubrication } \\
\text { Type }\end{array}$ & Textures & $\begin{array}{c}\text { Test time } \\
\text { (min) }\end{array}$ & $\begin{array}{c}\text { Lubricant } \\
\text { quantity } \\
(\mu \mathrm{L})\end{array}$ & $\begin{array}{c}\text { Mean sliding } \\
\text { speed } \\
(\mathrm{m} / \mathrm{s})\end{array}$ & $\begin{array}{l}\text { Load } \\
(\mathrm{N})\end{array}$ & $\begin{array}{c}\text { Temperature } \\
\left({ }^{\circ} \mathrm{C}\right)\end{array}$ \\
\hline 1 & Flooded & dimple & 10 & 500 & 0.05 & 150 & 20 \\
\hline 2 & Flooded & groove & 10 & 500 & 0.05 & 150 & 20 \\
\hline 3 & Flooded & smooth & 10 & 500 & 0.05 & 150 & 20 \\
\hline 4 & Starved & dimple & $\begin{array}{c}\text { until } \\
\text { lubrication } \\
\text { failure }\end{array}$ & 1.5 & 0.05 & 150 & 20 \\
\hline 5 & Starved & groove & $\begin{array}{c}\text { until } \\
\text { lubrication } \\
\text { failure }\end{array}$ & 1.5 & 0.05 & 150 & 20 \\
\hline 6 & Starved & smooth & $\begin{array}{c}\text { until } \\
\text { lubrication } \\
\text { failure }\end{array}$ & 1.5 & 0.05 & 150 & 20 \\
\hline
\end{tabular}




\subsection{Preparation of Textured Samples}

The plates were polished by $800 \#, 1000 \#, 1200 \#, 2400 \#$ and $4000 \#$ grades sand papers for 5 min respectively. Then these samples were polished with chemical polishing solution for 2 minutes [30]. The polished plate samples with surface roughness Ra of 4 10nm were obtained. After that, the polished steel plates were textured in the form of circular dimples and line grooves with a pico-second laser equipment. The diameter of the dimples $(d)$ and the width of the grooves $(\Delta W)$ were fixed as $45 \sim 50 \mu \mathrm{m}$ and $30 \mu \mathrm{m}$, while the depth of the dimples and grooves $(h)$ were changed in the range of $0.56 \sim 4.4 \mu \mathrm{m}$ and $2.5 \sim 12.2 \mu \mathrm{m}$ respectively. Both dimple and groove features were manufactured at three different distance $(L)$ to study the influence of the inter-feature distance. Circular dimples and line grooves with different center distances $(L)$ of $100 \mu \mathrm{m}, 150 \mu \mathrm{m}$ and $200 \mu \mathrm{m}$ were fabricated. For comparison, the texture-free lapped samples, $h=$ $0 \mu \mathrm{m}$, was also tested as a reference for bench marking.

Fig. 4 shows the topography profiles of circular-dimple textured surface with a depth of $2.5 \mu \mathrm{m}$ and center distance of $100 \mu \mathrm{m}$, and groove-textured surface with a depth of $10 \mu \mathrm{m}$ and center distance of $150 \mu \mathrm{m}$. As Fig.4 shown, the dimples and grooves were distributed uniformly on the polished surface. The white arrows in Fig.4.a. $\left(a_{1}\right)$ and Fig.4.b. $\left(b_{1}\right)$ and black arrows in Fig.4.a. $\left(\mathrm{a}_{3}\right)$ and Fig.4.b. $\left(\mathrm{b}_{3}\right)$ depict the sliding directions of textured plates.
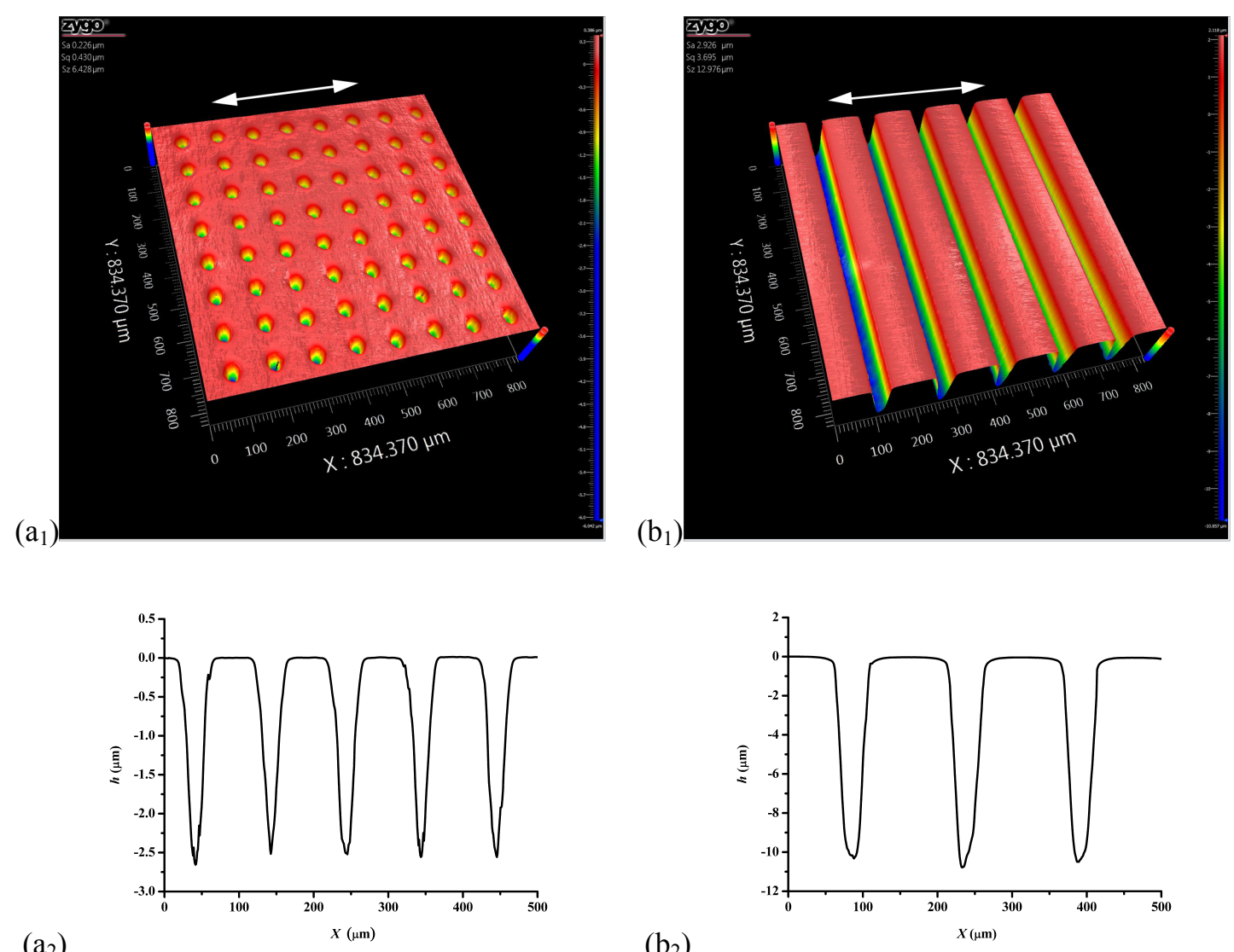

$\left(a_{2}\right)$

$\left(b_{2}\right)$

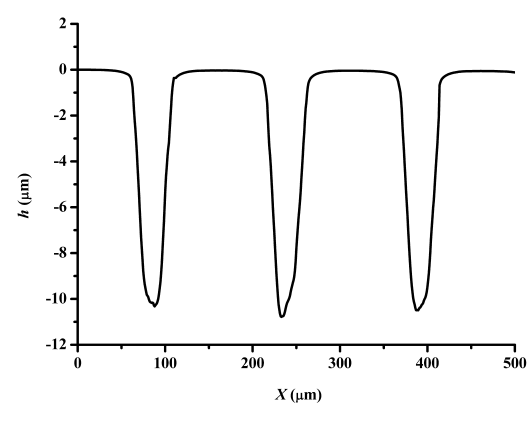


$\left(a_{3}\right)$

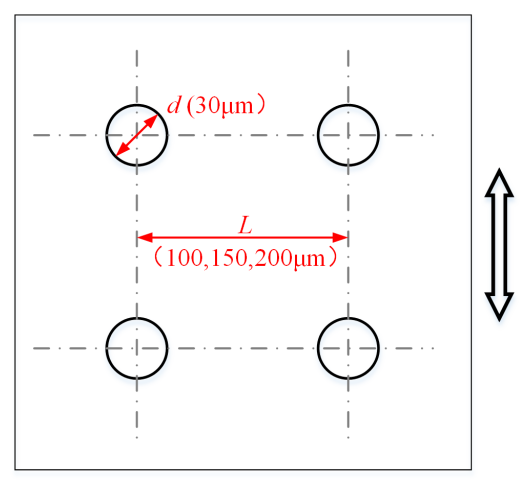

(a) Circular-dimple textured surface

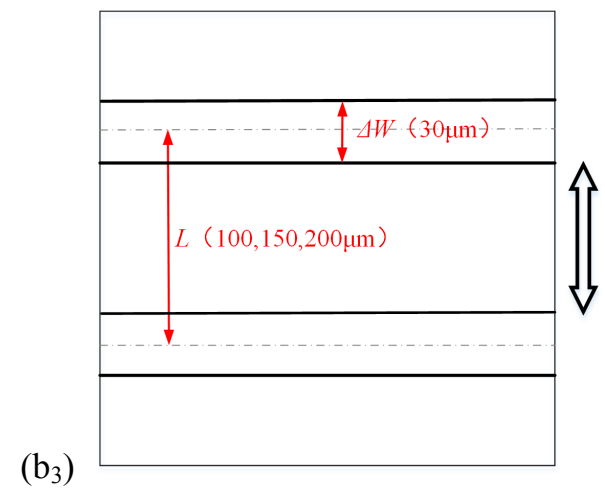

(b) Groove-textured surface

Fig.4 Topography profiles of textured surface

\subsection{Lubricant and additive}

Base oil with and without friction modifier MoDDP were used in the experiments. The base oil was a mixture of synthetic lubricating oil GTL8 (Shell (Shanghai) Technology Ltd., China) $80 \mathrm{wt} \%$ and of trimethylolpropane ester oil $20 \mathrm{wt} \%$. The trimethylolpropane ester was used to improve the solubility and dispersibility of MoDDP in the synthetic lubricating oil GTL8. MoDDP additive is a soluble friction modifier in commercial grade oil. Its molecular formula and the content of its characteristic elements Mo, S, P are presented in Fig.5 and Table.4 respectively.

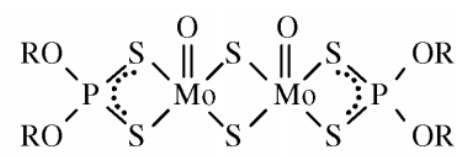

Fig.5 The molecular formula of MoDDP $(\mathrm{R}=$ alkyl group $)$

Table 4 Content of characteristic elements (wt $\%)$

\begin{tabular}{cccc}
\hline Additive & Mo & S & P \\
\hline MoDDP & 8.1 & 6.1 & 12.3 \\
\hline
\end{tabular}

Lubricant with various concentrations of MoDDP $(c=0.1 \mathrm{wt} \%, 0.25 \mathrm{wt} \%, 0.5 \mathrm{wt} \%, 1 \mathrm{wt} \%$, $3 \mathrm{wt} \%$ ) were prepared to study the influence of additive concentration on friction performance. The mixtures were stirred with a magnetic stirrer for at least $30 \mathrm{~min}$ before testing to ensure that the additive disperses well in the base oil. The viscosity $\left(\eta_{0}\right)$ is about $78 \mathrm{mPa} \bullet \mathrm{s}$ for all the oils used during this research with various concentrations of MoDDP. So the effect of MoDDP on lubricant viscosity and viscous friction is assumed negligible. 


\section{Experimental Results of Flooded Lubrication}

The film thickness ratio or $\lambda$ ratio, defined as the ratio of average film thickness over composite root-mean-square (RMS) roughness, is often used for estimation of lubrication state in a rough point contact. Here, Hamrock-Dowson formula, Eq. (1), is applied to calculate the minimum lubricant film thickness $h_{\min }[31]$.

$$
\mathrm{H}_{\text {min }}^{*}=3.63 R \frac{G^{* 0.49} U^{* 0.68}}{W^{* 0.073}}\left(1-e^{-0.68}\right)
$$

where, $\mathrm{H}_{\text {min }}^{*}=\frac{h_{\text {min }}}{R}, \mathrm{H}_{\text {min }}^{*}=\frac{h_{\text {min }}}{R}, \mathrm{G}^{*}=\alpha E^{\prime}, \mathrm{U}^{*}=\frac{\eta_{0} U}{E^{\prime} R}, \mathrm{~W}^{*}=\frac{\mathrm{w}}{\mathrm{E}^{\prime} \mathrm{R}^{2}}$. Under the experimental conditions during this study, the radius of the ball $R=5 \mathrm{~mm}$, the relative sliding speed $U=$ $0.05 \mathrm{~m} / \mathrm{s}$, the oil viscosity $\eta_{0}=78 \mathrm{mPa} \cdot \mathrm{s}\left(@ 20^{\circ} \mathrm{C}\right)$, the pressure-viscosity coefficient $\alpha=$ $2.2 \times 10^{-8} \mathrm{~m}^{2} / \mathrm{N}$, the equivalent-elastic-modulus $E^{\prime}=210 \mathrm{GPa}$, the applied load $W=150 \mathrm{~N}$. So the film thickness calculated with Eq. (1) is $h_{\min }=13.2 \mathrm{~nm}$.

Fig. 6 shows the 3D interferometry images of the ball and plate which have been used in this experiment. The RMS roughness of the ball and the plate are $20 \mathrm{~nm}$ and $4 \sim 10 \mathrm{~nm}$ respectively, so the composite RMS roughness is $\sigma=20.4 \sim 22.4 \mathrm{~nm}$. Therefore, the film thickness ratio $\lambda=h_{\min } / \sigma$ $<1$, which means that the friction pair operated in boundary lubrication region.

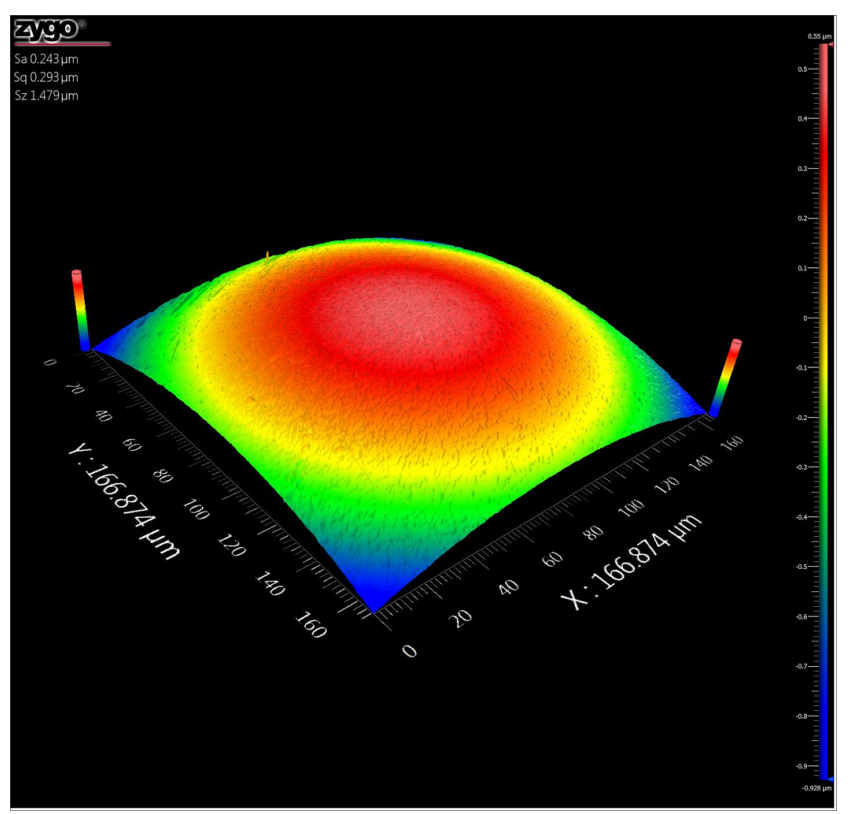

(a) ball 


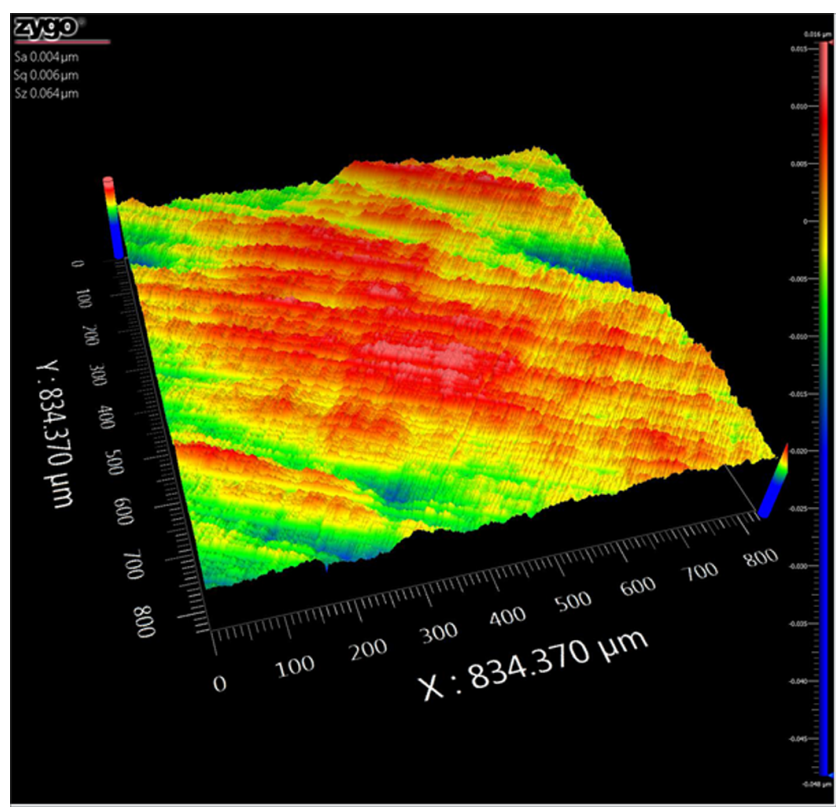

(b) plate

Fig.6 3D interferometry images and profiles of the ball and plate

\subsection{Circular-dimple textures}

(1) Dimple depth effect

Fig.7 shows the test results of friction performance of texture-free and circular-dimple surface with various depths. As shown in Fig.7 (a), when the base oil was used as a lubricant, the circular-dimple textured surfaces had a lower friction coefficient $(0.083 \sim 0.093)$ than the texture-free surface $(h=0)$. When the dimple depth was $0.9 \mu \mathrm{m}$, the friction coefficient was lower than that of the other shallower or deeper dimpled surfaces.

When the base oil with $0.5 \mathrm{wt} \%$ MoDDP was used as lubricant, the friction coefficient showed different trends compared to when only base oil was used, as shown in Fig.7 (b) Throughout the testing process, the friction coefficient was high at the initial stage and then reduced gradually for the texture-free surface $(h=0)$. However, for the textured surface with different circular depths, the friction coefficient decreased from about 0.09 at the initial stage to a lower value 0.05 0.07 after a short running-in time and kept almost constant for the remaining time. The friction coefficient drops fastest and reaches the lowest value among the tested dimpled samples for the surface with dimple depth of $2.5 \mu \mathrm{m}$. Comparing Fig.7 (b) with Fig.7 (a), it can be seen that the presence of $0.5 \mathrm{wt} \%$ MoDDP significantly enhances the dimple depth effect on friction coefficient or in other words a synergy effect between the dimple texturing and friction modifier exists. 


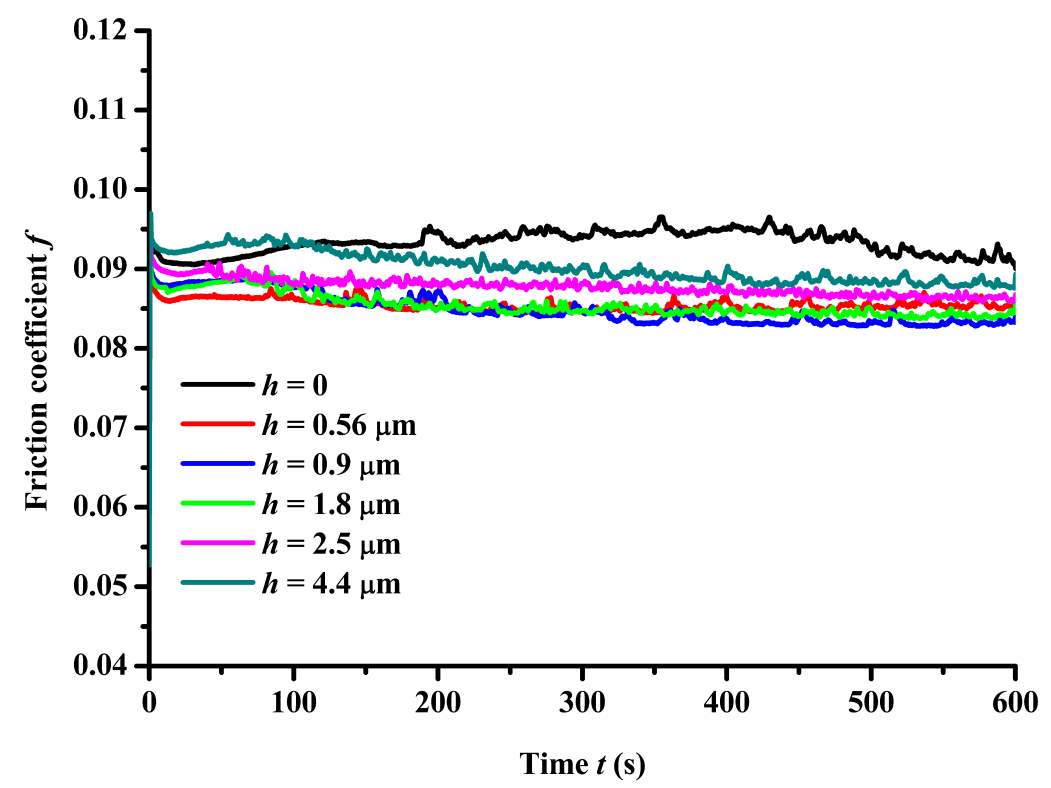

(a) base oil

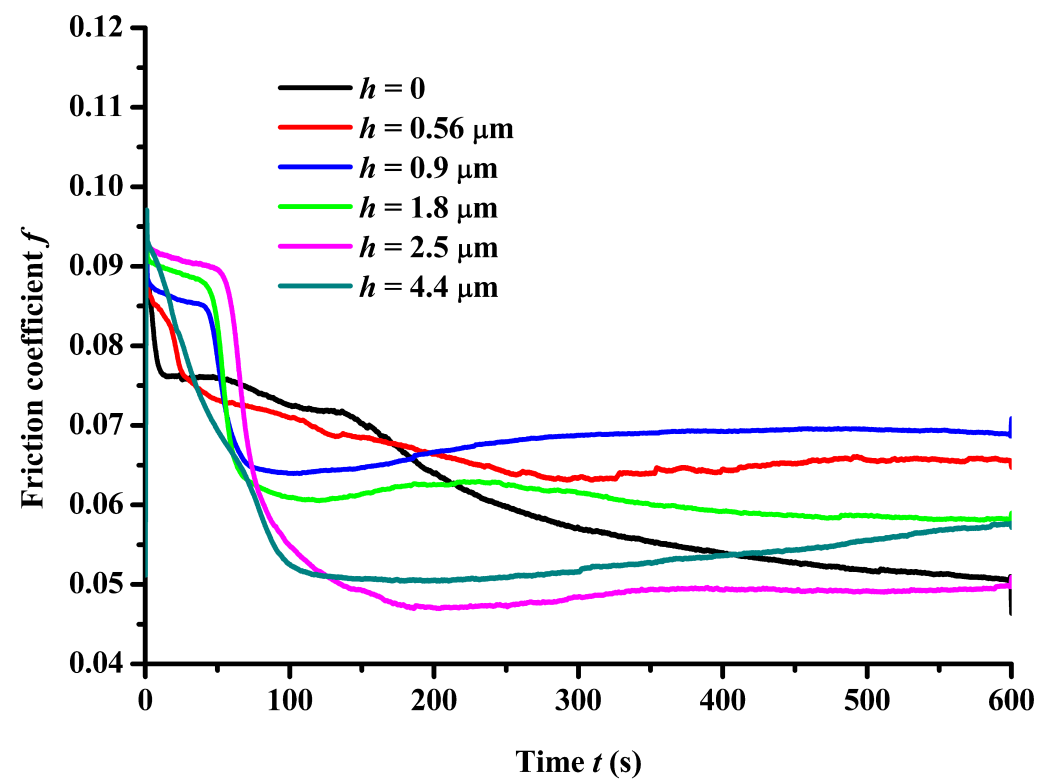

(b) base oil $+0.5 \mathrm{wt} \% \mathrm{MoDDP}$

Fig.7 Influence of dimple depth $(L=150 \mu \mathrm{m})$

(2) Center distance effect

Center distance between two adjacent dimples directly determines the density of dimples within the contact zone, and thus could affect the friction performance. Here, the depth of the dimples was fixed as $2.5 \mu \mathrm{m}$, while the center distance, $L$, was changed as $100 \mu \mathrm{m}, 150 \mu \mathrm{m}$ and 
$200 \mu \mathrm{m}$ respectively.

As Fig.8 (a) shows, when the base oil was used as lubricant, the friction coefficient of dimple textured surface with center distances of $100 \mu \mathrm{m}$ and $200 \mu \mathrm{m}$ were close to that of texture-free surface $(L=0)$ and approximately reached to the same value at the end of the tests $(0.09 \sim 0.095)$. When the center distance was $150 \mu \mathrm{m}$, the textured surface showed the best friction performance with lower friction coefficient of $0.087 \sim 0.09$. When $0.5 \mathrm{wt} \%$ MoDDP additive was contained in the lubricant, the friction coefficient decreased from about 0.09 to lower values after several minutes during the test, as shown in Fig.8 (b). When the center distance was $150 \mu \mathrm{m}$, the friction coefficient was smaller than that of the texture-free surface. When the center distances were $100 \mu \mathrm{m}$ and $200 \mu \mathrm{m}$, the friction coefficients were larger than that of the texture-free surface.

When MoDDP additive is present, the dimple's center distance has a much stronger effect during the running-in stage and the level of steady friction on the friction coefficient, in terms of its reduction as shown in Fig.7 comparing to base oil. The center distance of $150 \mu \mathrm{m}$ is the best among all of the tests from the friction reduction view point.

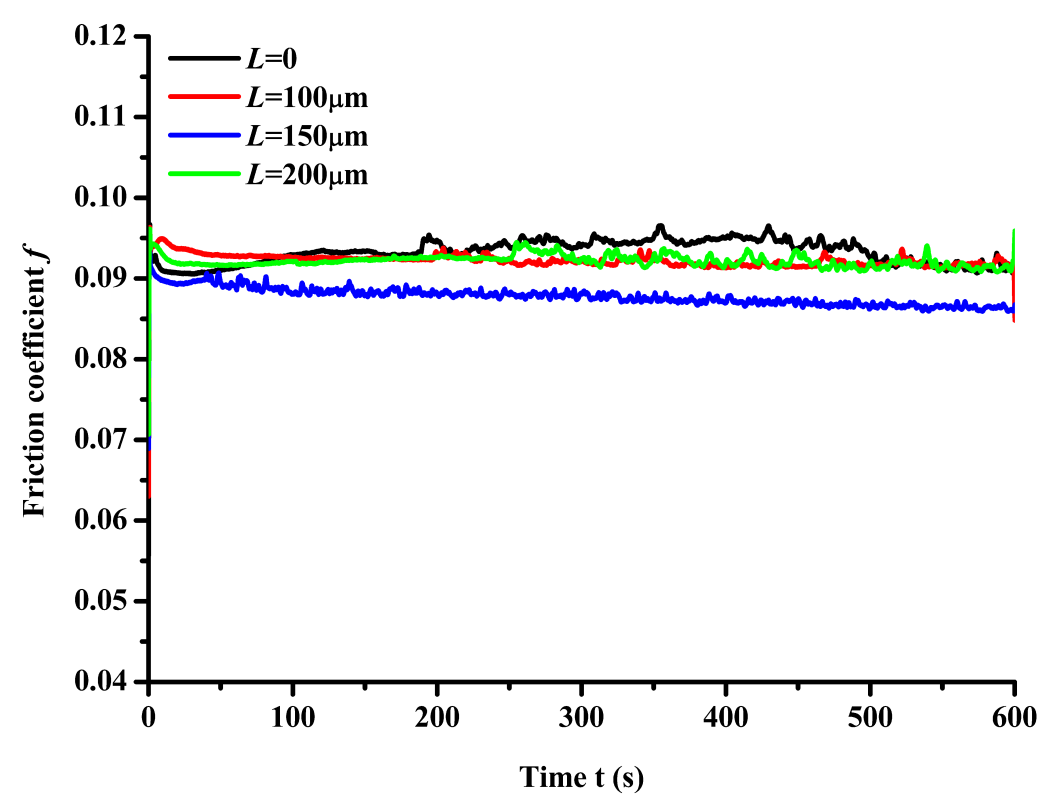

(a) base oil 


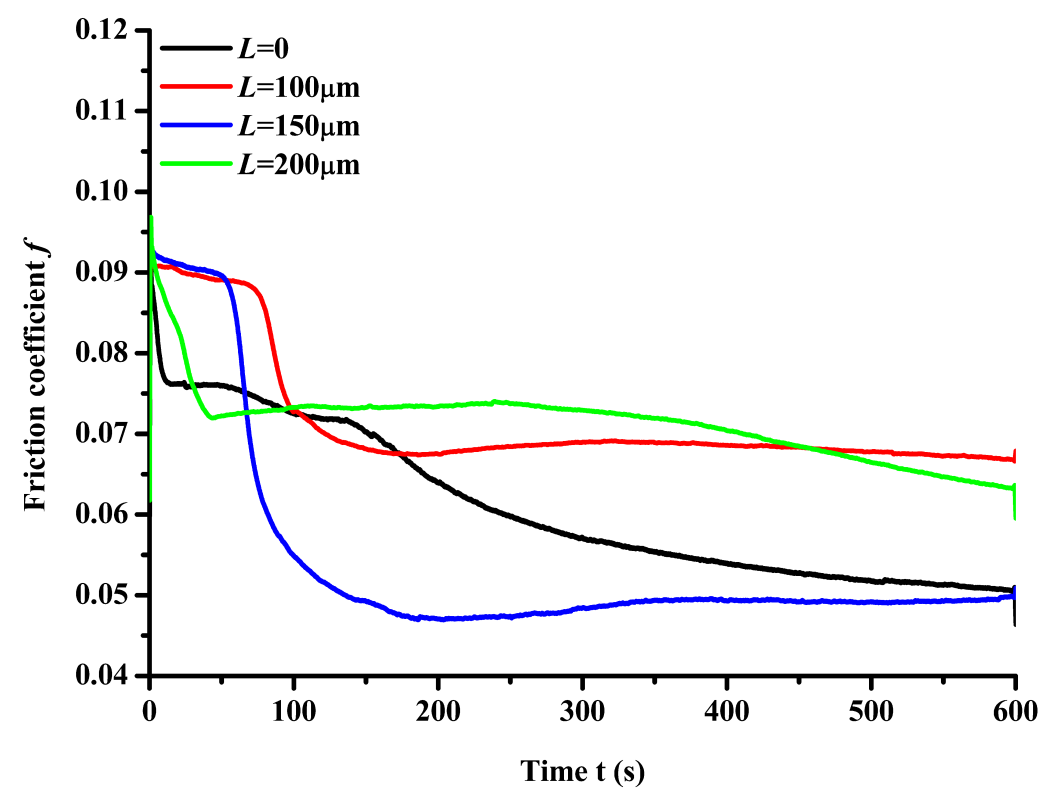

(b) base oil $+0.5 \mathrm{wt} \% \mathrm{MoDDP}$

Fig. 8 The influence of dimple center distance $(h=2.5 \mu \mathrm{m})$

(3) Additive concentration effect

It has previously been reported that MoDDP concentration is an important factor which influences tribofilm formation [9]. In this study, experiments were performed by using various MoDDP mass concentrations of $0 \%$ (base oil), $0.1 \mathrm{wt} \%, 0.25 \mathrm{wt} \%, 0.5 \mathrm{wt} \%, 1 \mathrm{wt} \%$ and $3 \mathrm{wt} \%$. The friction coefficient was around 0.09 0.095 when the MoDDP concentration was $0.1 \mathrm{wt} \%$ for the texture-free surface. This is almost the same as that of the base oil which is $0 \mathrm{wt} \%$. The friction coefficient gradually decreased to 0.05 and 0.06 when the concentration of MoDDP was increased to $0.25 \mathrm{wt} \%$ and $0.5 \mathrm{wt} \%$ respectively. When the concentration further increased to $1 \mathrm{wt} \%$, the friction coefficient decreased from about 0.075 at the initial stage to a lower value of 0.055 after a short running-in time and remaining almost constant for the rest of the testing. However, when the concentration was increased to $3 \mathrm{wt} \%$, the friction coefficient was more than that of the concentrations $0.1 \mathrm{wt} \% \sim 1 \mathrm{wt} \%$ at the end of the tests. Hence it is deduced that he optimal concentration value of MoDDP is $0.5 \mathrm{wt} \%$ in the test conditions.

As shown in Fig.9 (b) the dimple texturing does not change the trend significantly. The relationship between the friction coefficient and MoDDP concentration for the dimple-textured surface was similar in trend to that of the texture-free surface, especially when the concentration is lower than $0.25 \mathrm{wt} \%$. For the higher concentrations, the running-in of the dimpled surfaces is quicker to some extent than the texture-free surfaces.

From the experimental results it is conclude that there is a threshold of the MoDDP 
concentration in terms of saturation point. Beyond this threshold the MoDDP has very little to contribute for further reduction of the friction coefficient for both textured and texture-free surfaces. These results are consistent with the previous study [9] which was only focused on texture-free surfaces.

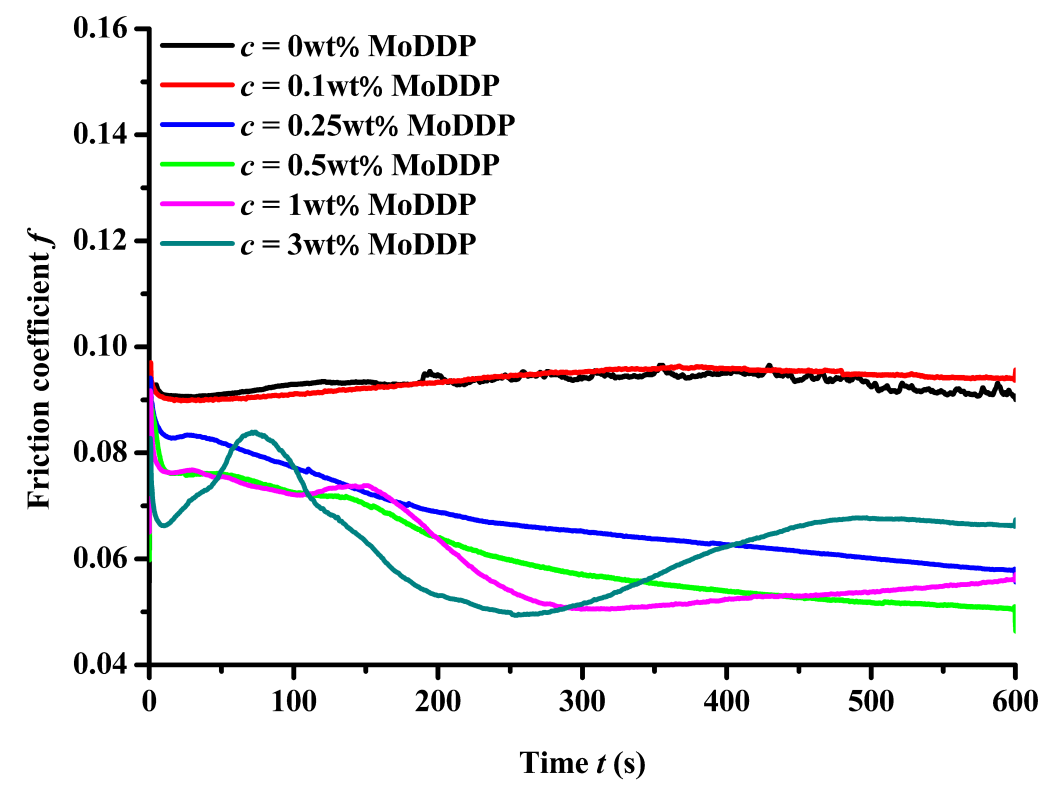

(a) texture-free

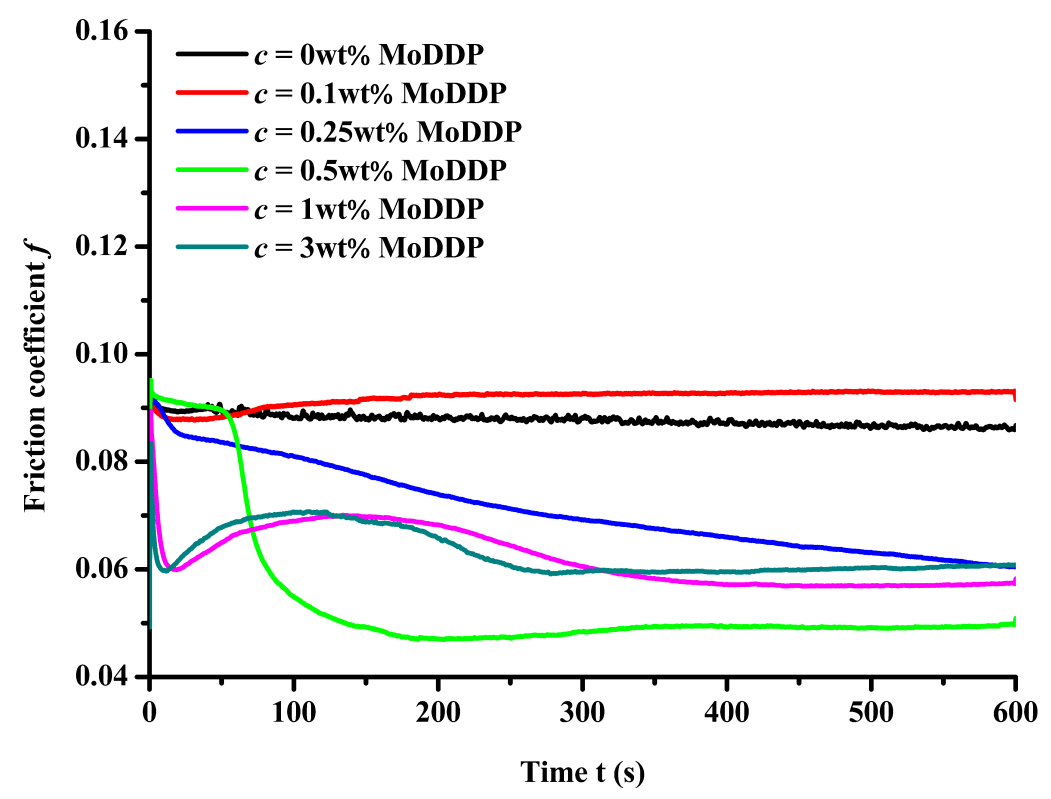

(b) circular dimple

Fig.9 The influence of concentration $(h=2.5 \mu \mathrm{m}, L=150 \mu \mathrm{m})$ 


\subsection{Groove textures}

(1) Groove depth effect

For the grooved samples, friction coefficient was larger than that of the texture-free sample when no MoDDP was used as shown in Fig.10 (a). The friction coefficient remained almost constant, 0.095-0.105, throughout the experiment for the texture-free and all the grooved surfaces. After adding $0.5 \mathrm{wt} \%$ MoDDP additive to the lubricant, the friction coefficient fell from around 0.11 to a lower value about 0.05 after running-in for several minutes. When the depth of the groove was $2.5 \sim 10 \mu \mathrm{m}$, the friction coefficient was smaller than that of the texture-free surface and reached to a minimum value of around 0.045 at the depth of $10 \mu \mathrm{m}$. This is shown in Fig.10 (b).

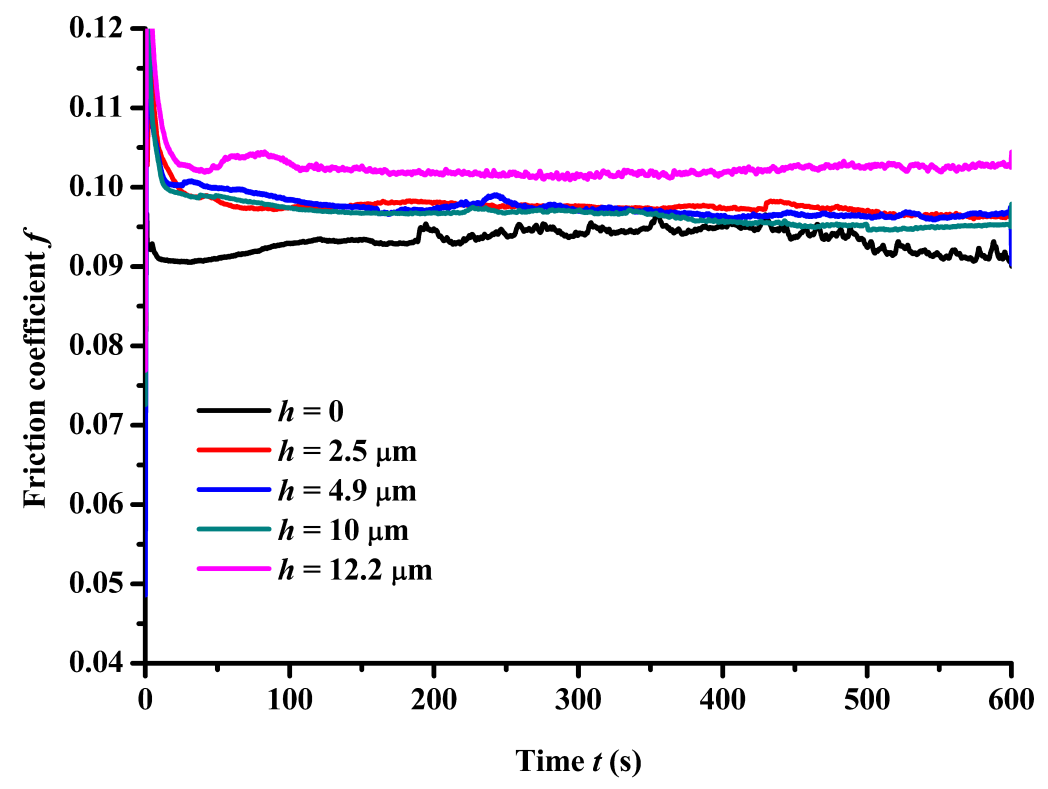

(a) base oil 


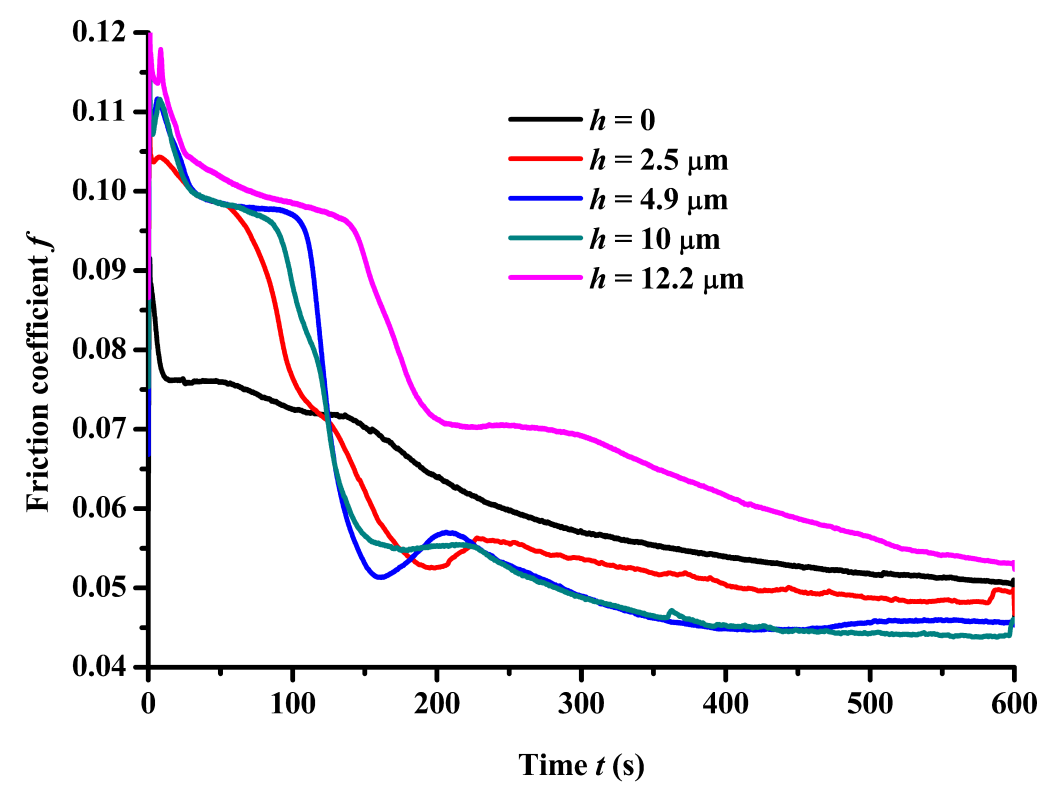

(b) base oil $+0.5 \mathrm{wt} \% \mathrm{MoDDP}$

Fig.10 The influence of groove depth $(L=150 \mu \mathrm{m})$

\section{(2) Center distance effect}

In this test, the groove depth was kept at $10 \mu \mathrm{m}$ with various center distances of $100 \mu \mathrm{m}$, $150 \mu \mathrm{m}$ and $200 \mu \mathrm{m}$. As Fig.11 (a) shows, the friction coefficient of groove textured surfaces with varying center distance was $0.1 \sim 0.145$, more than that of the texture-free surface when the base oil was used as a lubricant. While, when $0.5 \mathrm{wt} \%$ MoDDP was contained in the lubricant, the friction coefficient was large at first and then fell sharply for both texture-free and groove textured surfaces. There was an optimal center distance of $150 \mu \mathrm{m}$ for improving friction performance. However, unlike in the base oil condition, the friction coefficient of groove surface with center distance of $150 \mu \mathrm{m}$ was smaller than the texture-free surface when $0.5 \mathrm{wt} \%$ MoDDP contained in the lubricant. Based on the above evidence it can be stated that it was the synergetic effects of groove texture and friction modifier which significantly improved the friction performance. 


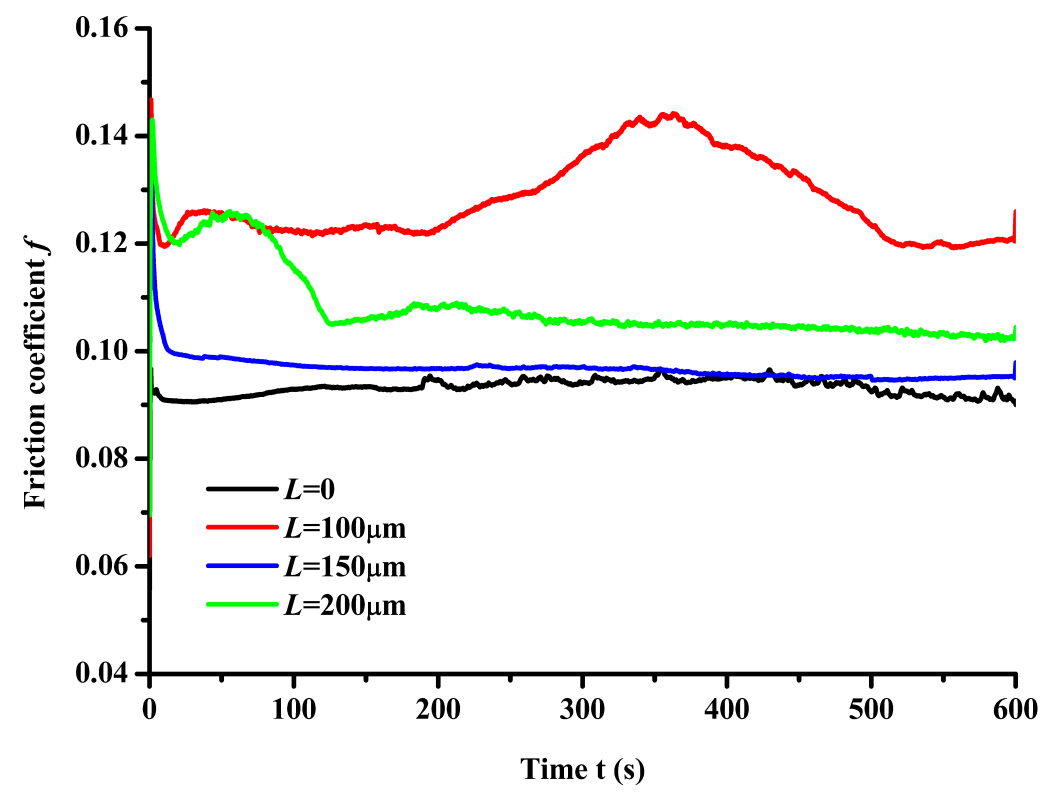

(a) base oil

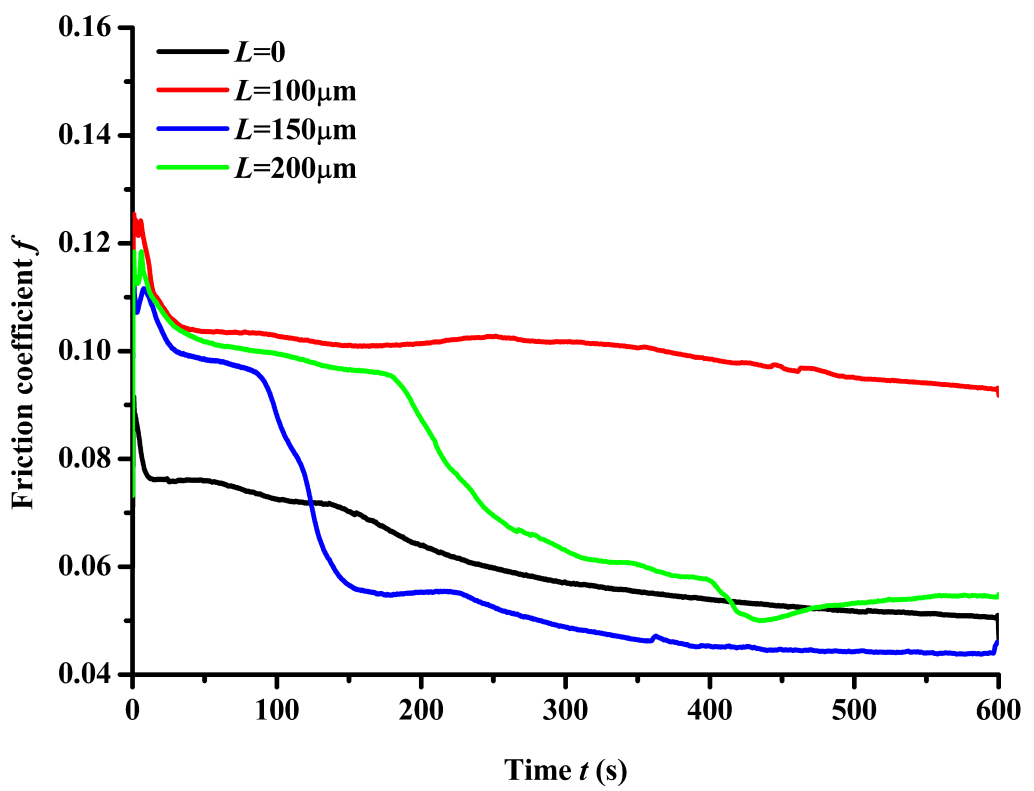

(b) base oil $+0.5 \mathrm{wt} \% \mathrm{MoDDP}$

Fig.11 The influence of groove center distance $(h=10 \mu \mathrm{m})$

(3) Additive concentration effect

As shown in Fig.12, when the concentration was $0.1 \mathrm{wt} \%$, the friction coefficient remained around 0.1 during experiment, almost the same as that in the base oil $(0 \mathrm{wt} \%)$. When MoDDP 
concentrations were $0.25 \mathrm{wt} \%, 1 \mathrm{wt} \%$ and $3 \mathrm{wt} \%$ the friction coefficient of groove textured surface showed the same trend throughout the test as that of the $0.5 \mathrm{wt} \%$ concentration which was been described earlier. As the concentration increased, the friction coefficient first decreased and then increased and reached the optimal value when the concentration was $0.5 \mathrm{wt} \%$. This rule was the same as that of the texture-free and circular-dimple textured surface. In addition, it is noteworthy that the higher the concentration, the faster the friction coefficient tend to decrease from a relatively high value.

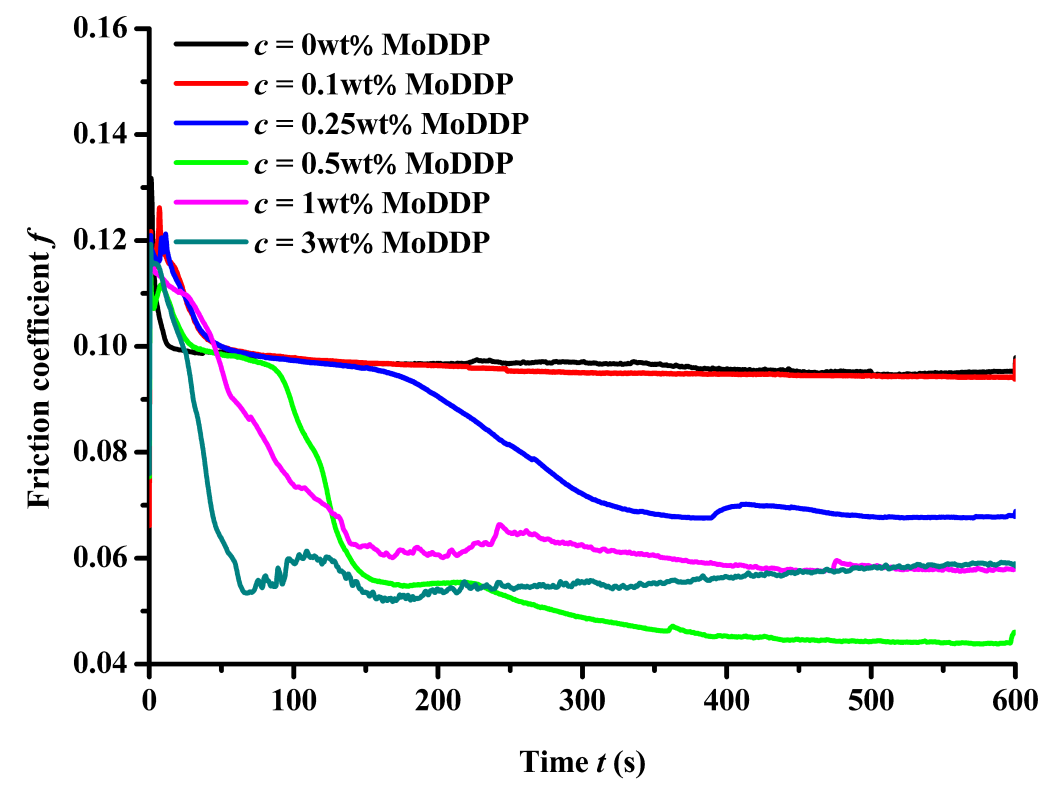

Fig.12 Influence of concentration ( $h=10 \mu \mathrm{m}, L=150 \mu \mathrm{m})$

\section{Experimental results of starved lubrication}

Starved lubrication was realized by covering the top surface of the plate samples with a thin layer of lubricating oils as shown in Fig.2 and Fig.3. Circular-dimple textures and groove textures with the optimal geometric parameters (for circular dimple $h=2.5 \mu \mathrm{m}, L=150 \mu \mathrm{m}$ and for groove $h=10 \mu \mathrm{m}, L=150 \mu \mathrm{m}$ ) obtained in Section 3 were selected in this starved lubrication experiments. The friction tests were conducted under the same load and speed as in the flooded lubrication conditions until an abrupt increase of friction coefficient was detected. The time period till the sudden increase of the friction coefficient is considered here as the life span of the test sample. Each test was repeated for two times and the results were all presented to make sure the experimental repeatability. 


\subsection{Circular dimples}

As shown in Fig.13, friction coefficient started at the initial value of about 0.1 whether or not MoDDP was added in the lubricant and went up abruptly after a period of test. When the base oil was used as a lubricant, the life span of the texture-free samples was $44 \mathrm{~s}$ and $57 \mathrm{~s}$ respectively in two repeated tests and this was prolonged to $163 \mathrm{~s}$ and $164 \mathrm{~s}$ respectively under the same operating conditions for dimpled surfaces as shown in Fig.13 (a). This means that the dimples can prolong the life span up to $3 \sim 4$ times. When $0.5 \mathrm{wt} \%$ MoDDP additive was added in the base oil, the lifespan was $131 \mathrm{~s}, 131 \mathrm{~s}$ for the texture-free surface and 3502s, 3710s for the dimple textured surface in two repeated tests as shown in Fig.13 (b). This implied the life span of dimpled surfaces was between 26-28 times longer than the texture-free surface.

Summarizing the above results, it can concluded that there is a synergetic effect of the dimple and friction modifier, which is greater than the single effect of only textures ( $3 \sim 4$ times increase in life span, from $44 \mathrm{~s}, 57 \mathrm{~s}$ to $164 \mathrm{~s}, 163 \mathrm{~s}$ ) or only MoDDP additive (2 3 times increase in life span, from $44 \mathrm{~s}, 57 \mathrm{~s}$ to $131 \mathrm{~s}, 131 \mathrm{~s})$.

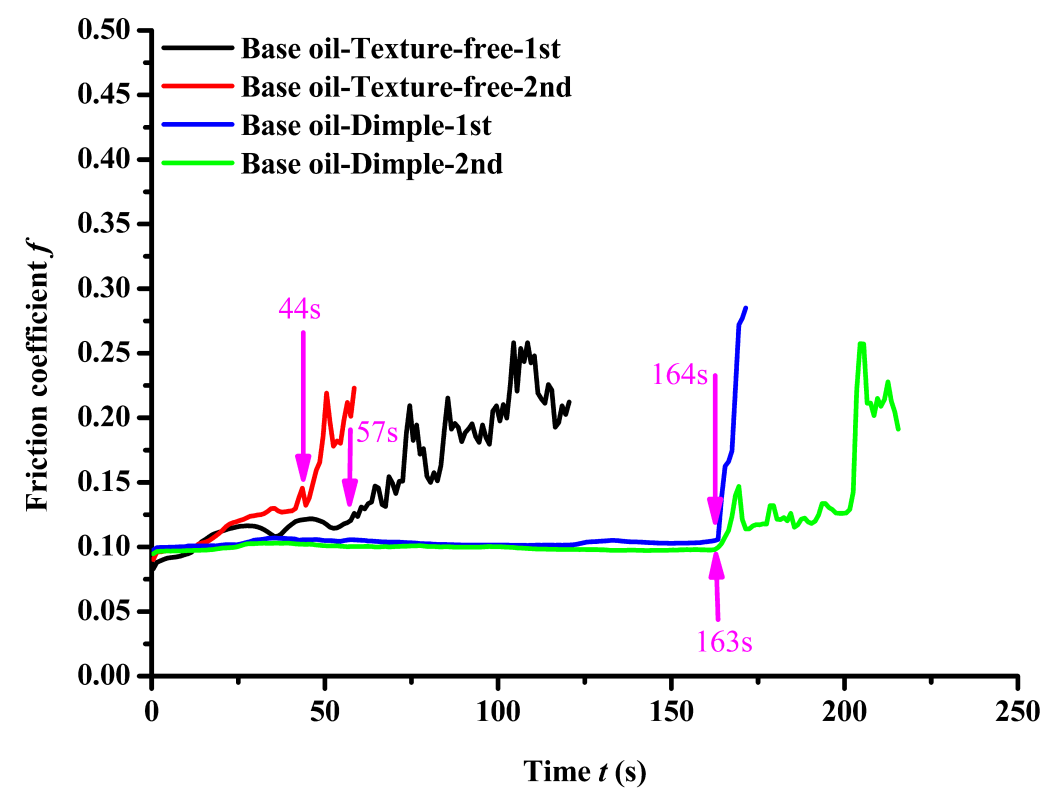

(a) base oil 


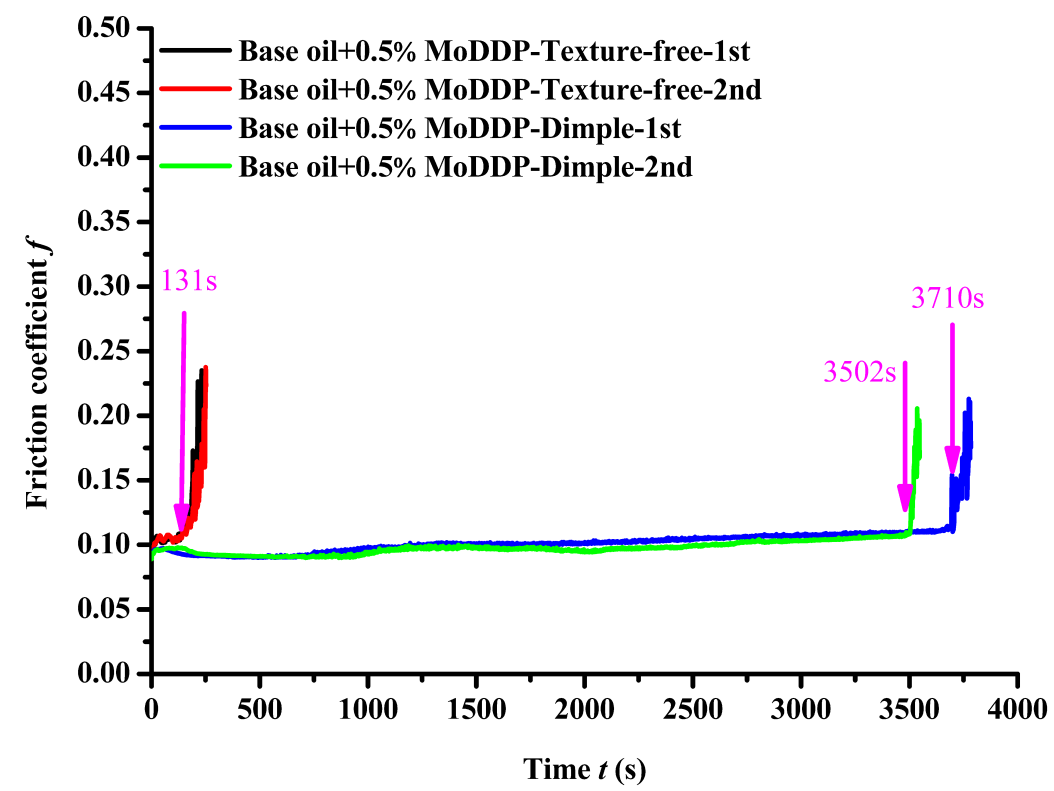

(b) base oil $+0.5 \mathrm{wt} \% \mathrm{MoDDP}$

Fig.13 Friction performance under starved lubrication conditions (dimple)

\subsection{Grooves}

Fig.14 shows the friction performance of grooved surfaces under starved lubrication conditions with and without MoDDP additive. As Fig.14 (a) shows, the lifespan can be increased to $1960 \mathrm{~s}$ and $2615 \mathrm{~s}$ in two repeated tests if line groove textured surface with depth of $10 \mu \mathrm{m}$ was used. Comparing to the texture-free surface, this means between 34 60 times increase in life span. When $0.5 \mathrm{wt} \%$ MoDDP additive was added in the base oil, the lifespan of groove textured surface can be further increased up to 4380 and 5000s, twice as long as in the base oil, as shown in Fig.14 (b).

In summary, the synergetic effects of groove textures and $0.5 \mathrm{wt} \%$ MoDDP can prolong lifespan of test samples for 77 114 times (from 44s, 57s to 4380s, 5000s). Meanwhile, it can be seen that the grooved samples are more effective in starved lubrication than the dimpled surfaces. This may be attributed to more lubricant storage for the line groove textures. 


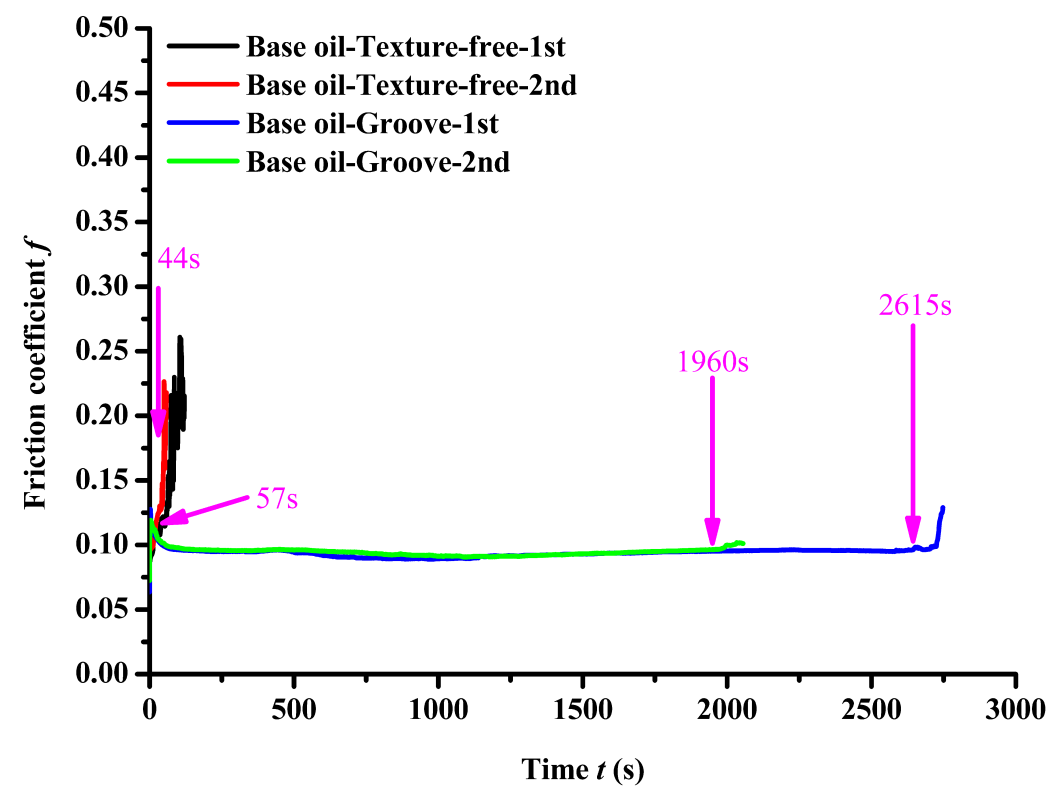

(a) base oil

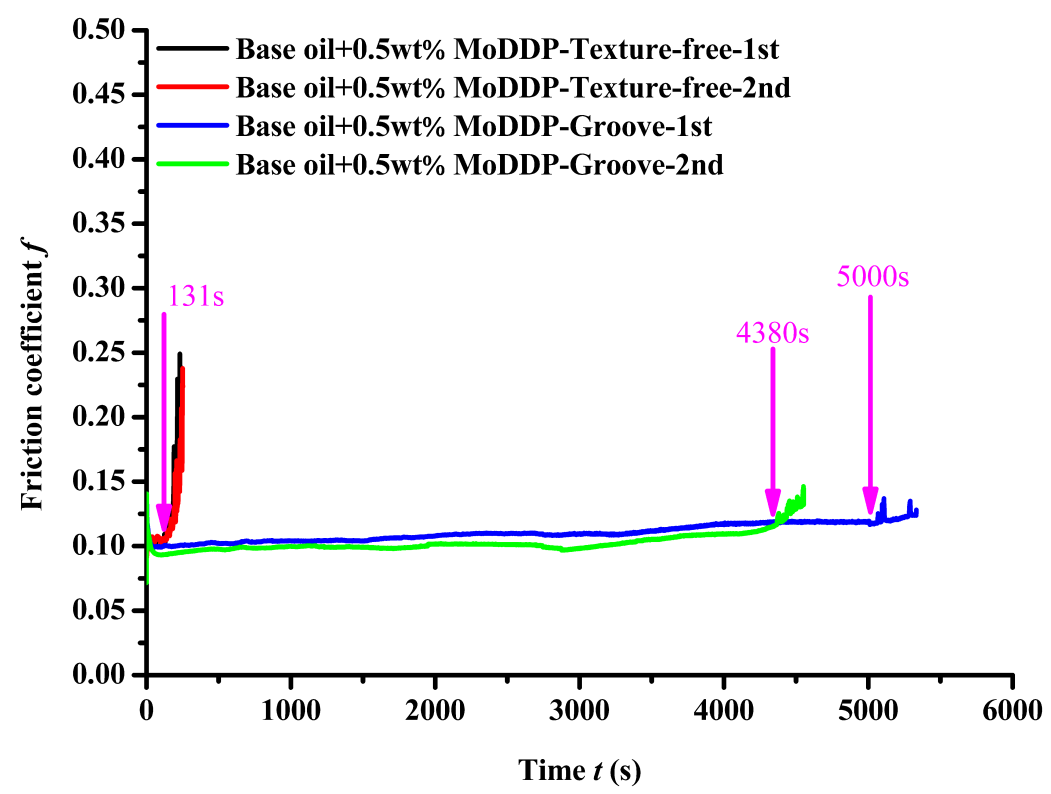

(b) base oil $+0.5 \mathrm{wt} \% \mathrm{MoDDP}$

Fig.14 Friction performance under starved lubrication conditions (groove)

\section{Discussions}

\subsection{Flooded lubrication}

The reaction films can produce ultra-low friction coefficient from a relatively higher value 
after a short running-in time due to the MoDDP characteristics when subjected to flooded lubrication [8]. Usually, this running-in process was called induced period. Though this law mainly governs texture-free surface, it is also applicable to circular dimple and groove textured surfaces as shown in Fig.7 Fig.12. These figures suggest that textures mainly influence the induced period and the corresponding final friction coefficient. For circular dimple textures with various depths and center distances as shown in Fig.7 (b) and Fig.8 (b), the induced period was shortened compared to the texture-free surface. The induced period for the groove surface was longer $(L=100 \mu \mathrm{m}, 200 \mu \mathrm{m})$ or shorter $(L=150 \mu \mathrm{m})$ than that of texture-free surface with different depths and center distances as shown in Fig.12 (b) and Fig.13 (b). Fig.15 shows the induced period of texture-free surface and textured surfaces with different depths. The induced period of texture-free surface was about 150s, which was longer than the textured surfaces with induced period of less than $50 \mathrm{~s}$. In addition, during the induced period, the friction coefficient of textured surface was larger than that of the texture-free surface.

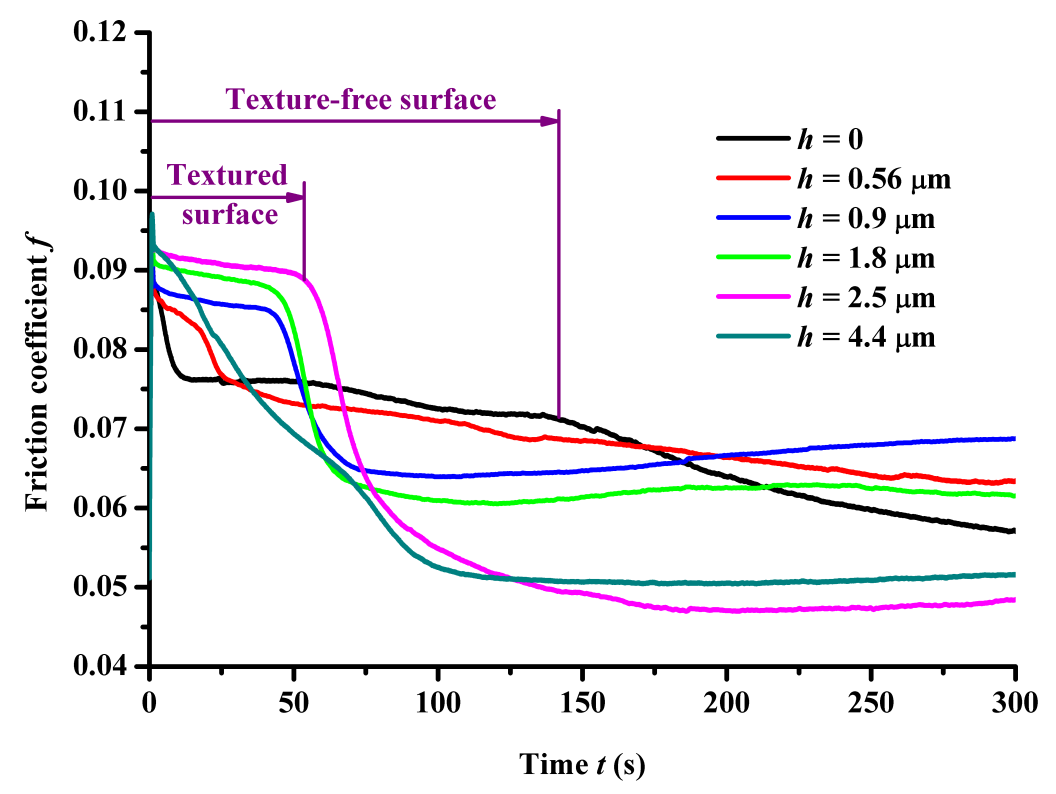

Fig. 15 Induced period of dimple textured surfaces with different depth (base oil $+0.5 w t \% M o D D P$,

$$
L=150 \mu \mathrm{m})
$$

Except for the difference in induced period, the final friction coefficient was more sensitive to texture parameters when MoDDP was contained in the lubricant than when only base oil was used. When the base oil was used as a lubricant, the friction coefficient of circular-dimple textured surfaces and grooved samples were 0.085-0.095 (Fig.7 (a) and Fig.8 (a)) and 0.09-0.12 (Fig.10 (a) and Fig. 11 (a)) respectively. When $0.5 \mathrm{wt} \%$ MoDDP was contained in the lubricant, the friction 
coefficient for the textured surface decreased to lower values of 0.05-0.09 (Fig.7 (b) and Fig.8 (b)) and 0.045-0.11 (Fig.10 (a) and Fig.11 (a)) respectively and remaining almost constant in the remaining time after induced period. So the difference in friction coefficient for the dimple-textured surface with various geometric parameters is 3 times of that for a texture-free surface. Meanwhile, this value is also up to 2 times for the groove-textured surface.

The above various friction performances described between the textured surface and texture-free surface can be explained by the effect of surface textures on the formation of MoDDP tribofilms. Fig.16 shows a typical MoDDP tribofilm structure formed on the asperities. It is widely accepted that on the sliding surface, $\mathrm{Fe}$ phosphate, $\mathrm{FeS}$ and $\mathrm{MoO}_{3}$ were formed on the fresh metal surface and worked as antiwear tribofilms. At the same time, nanosheets of $\mathrm{MoS}_{2}$ formed between the sliding surfaces and then lead to smaller friction coefficient. Previous research showed that contact pressure was a critical parameter that influenced the friction performance of soluble molybdenum-containing compounds. The friction coefficient appears to drop only when solidsolid rubbing occurs at high pressures or with rough surfaces due to stress-assisted tribochemical reaction [32]. Some research showed that there was relatively high stress at the edge of textures $[33,34]$. The texture parameters directly influence the pressure distribution in the contact region. Fig.17 shows the schematic comparative diagrams of pressure distribution of texture-free surface and textured surface. The contact pressure at the edge of the textures is larger than that of texture-free surface. Then, it can be reasonably extrapolated that the high contact pressure or relatively high stress at the edge of textures promote the generation of MoDDP triboflims and nanosheets of MoS2, thus affect the induced period of textured surface. However, the high contact pressure caused by larger area ratio or smaller center space may increase the friction coefficient. When the reducing friction effect of MoS2 exceed the increasing effect of center space, the friction coefficient began to drop. In this research, circle dimples with different depth and center spaces had shorter induced period than the texture-free surface. While, for the groove textures, only surface with center distance of $150 \mu \mathrm{m}$ had shorter induced period.

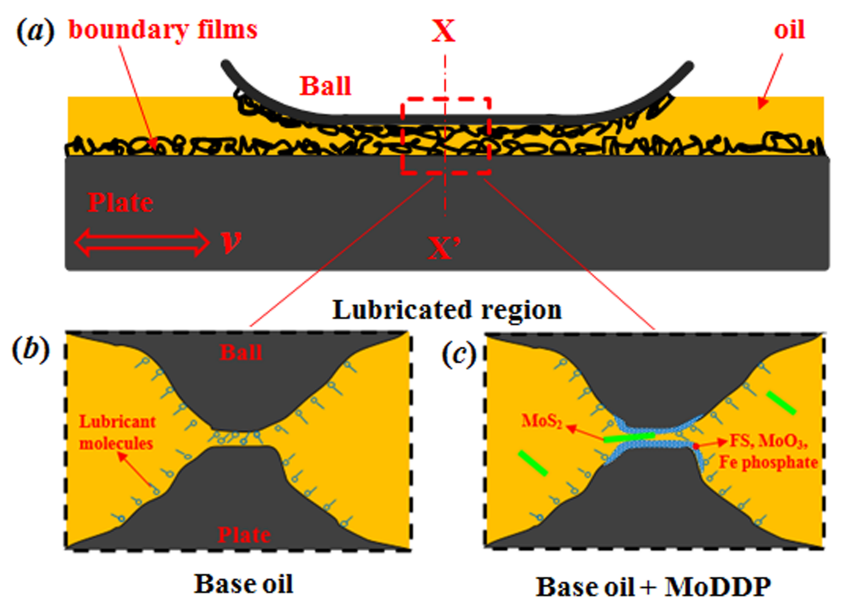


Fig.16 Boundary film structures

(at asperity contact an exploded cross-sectional view at XX' shown in Fig.16.(b) and Fig.16.(c))

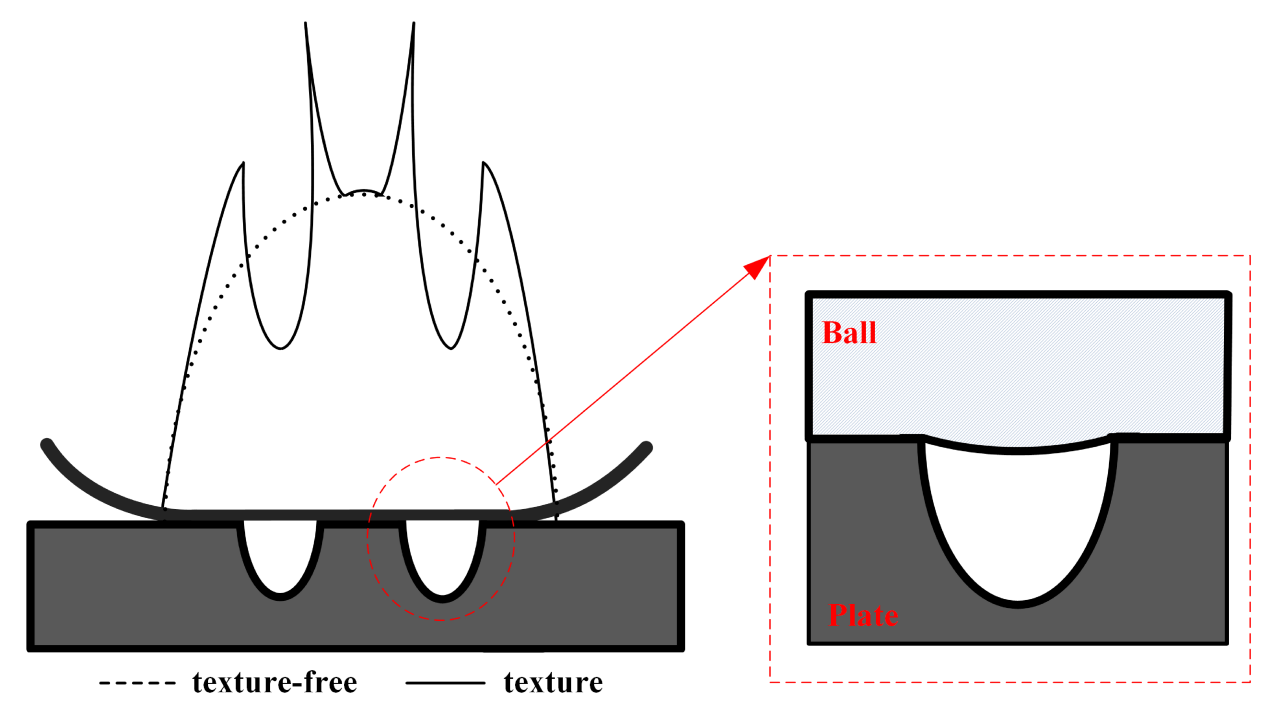

Fig. 17 Contact pressure distribution

The friction coefficients of textured surfaces with various geometrical parameters have no obvious difference when base oil was used as a lubricant because textures provide almost no hydrodynamic effect under boundary lubrication. However, when MoDDP was contained in the lubricant, the friction coefficients were more sensitive to texture parameters. Except for the hypothesis of pressure activation described before, some research illustrated that under extreme conditions, the deformation of the material around the textures causes the volume of the textures to decrease, forcing the oil to flow out of the texture and then lubricate the surfaces [35]. This means that more additives can be provided to the contacting area from the textures. However, the lubricant extraction was affected by texture parameters [36]. Therefore, the friction coefficients were more sensitive to texture parameters when MoDDP was contained in the lubricant than that of the base oil. Meanwhile, surface textures can store solid wear particles during sliding process to prevent the tribofilms from being destroyed by abrasive particles. So the friction coefficient can keep constant for a long sliding time.

The wear scar morphologies of three different kinds of surfaces and corresponding counter-faces of balls after friction tests with and without MoDDP in the base oil are shown in Fig.18. The texture parameters of dimples and grooves are the optimal values obtained in this study. The depth of wear scars are $0.2 \mu \mathrm{m}, 0.3 \mu \mathrm{m}, 2.75 \mu \mathrm{m}$ for texture-free surface, dimple textured surface and groove textured surface respectively when base oil was used as lubricant. This means that the dimples and grooves have no anti-wear effect subject to this operating conditions. This is 
because under boundary lubrication conditions, the protrusion on the ball is easily embedded in the textures as shown in Fig.17 and caused surface abrasions during the relative sliding process. However, when $0.5 \mathrm{wt} \%$ MoDDP was added in the lubricant, the depth of wear scars decreased to $0.125 \mu \mathrm{m}, 0.15 \mu \mathrm{m}$ and $0.275 \mu \mathrm{m}$, which are $62.5 \%, 50 \%$ and $10 \%$ of the corresponding values when just base oil was used. So, it is the synergetic effect of surface textures and MoDDP which improve the wear performance.
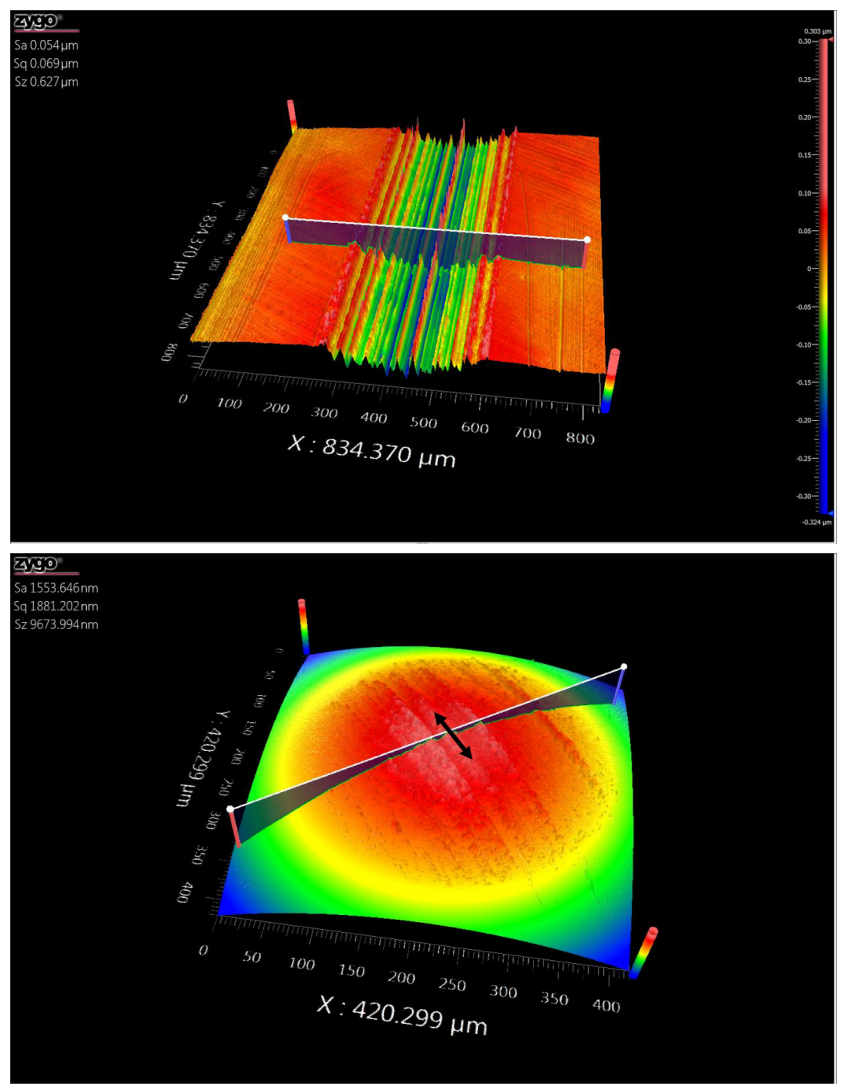

$\left(a_{1}\right)$

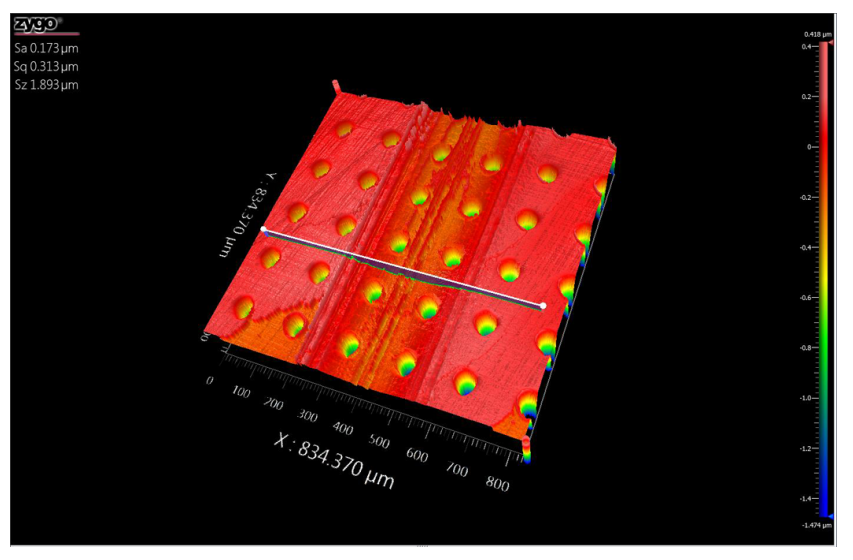




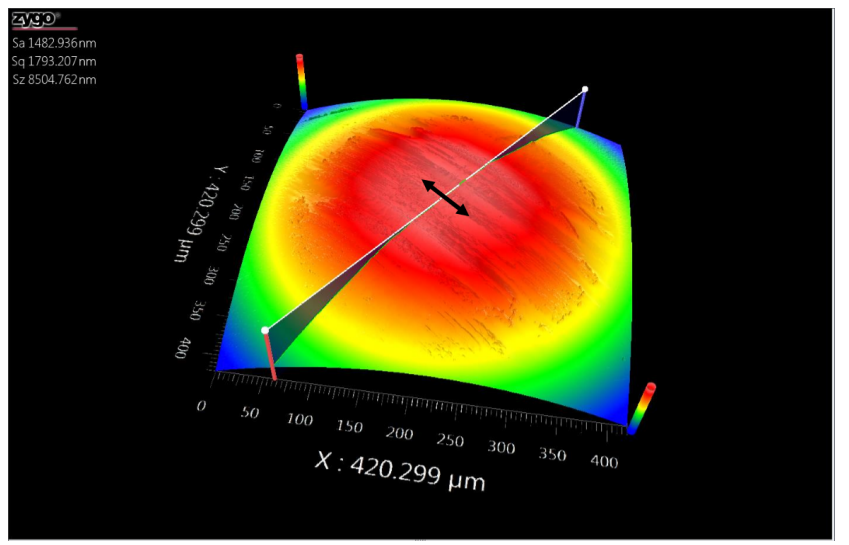

$\left(a_{2}\right)$
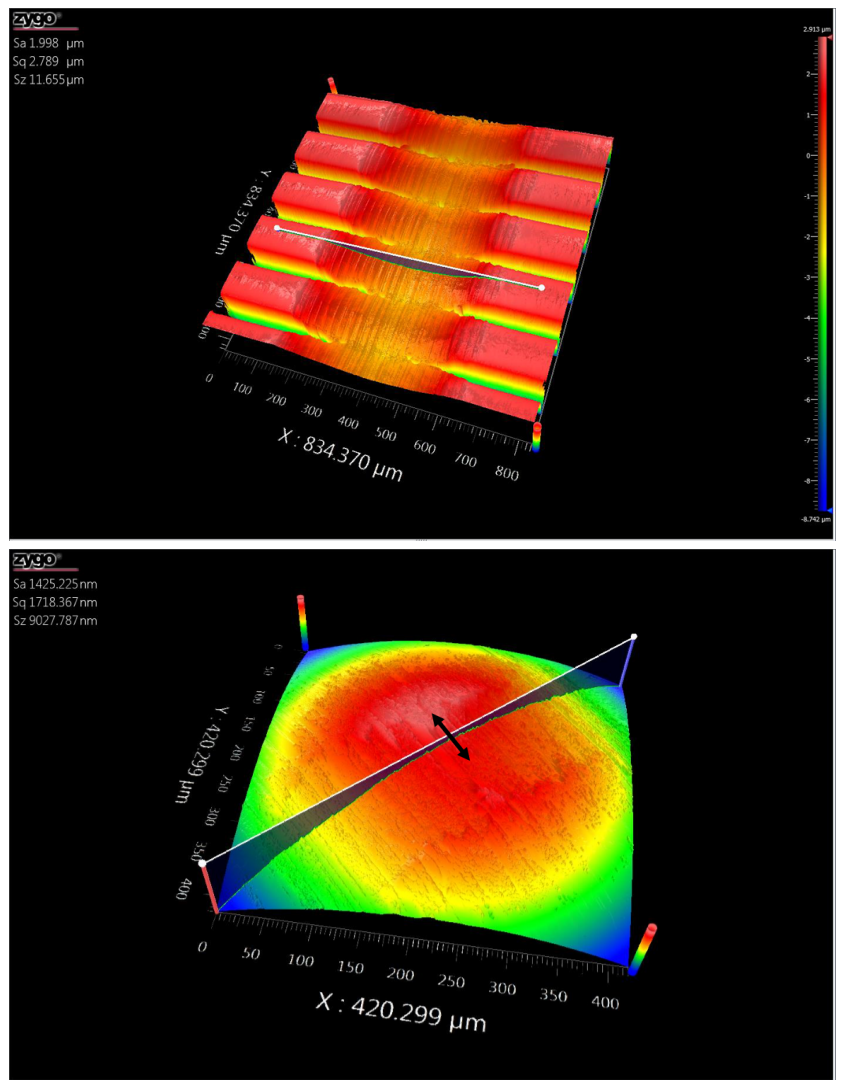

$\left(a_{3}\right)$

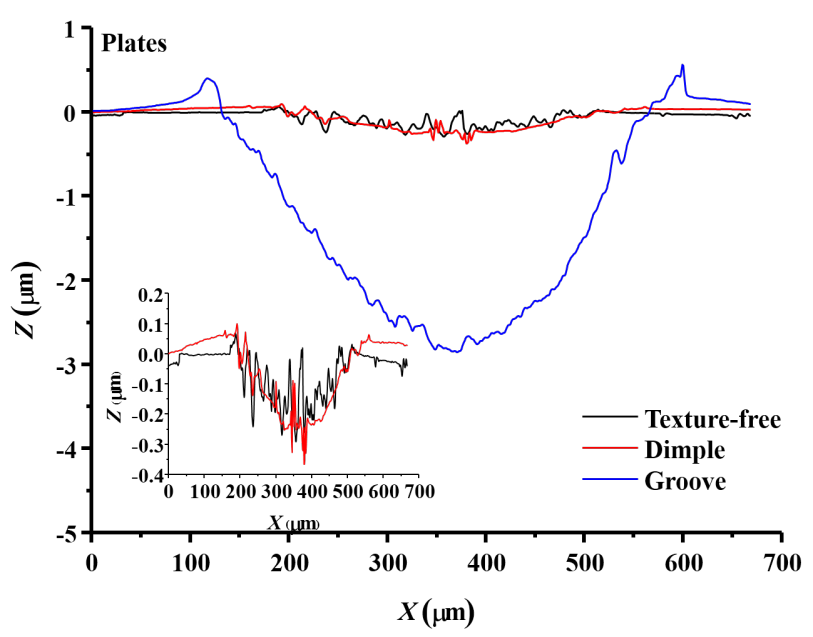




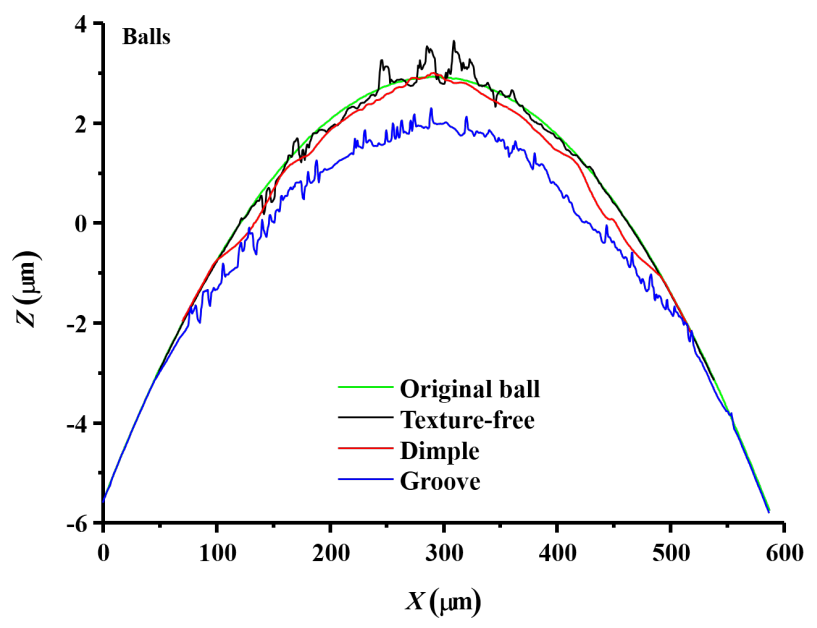

$\left(a_{4}\right)$

(a) base oil

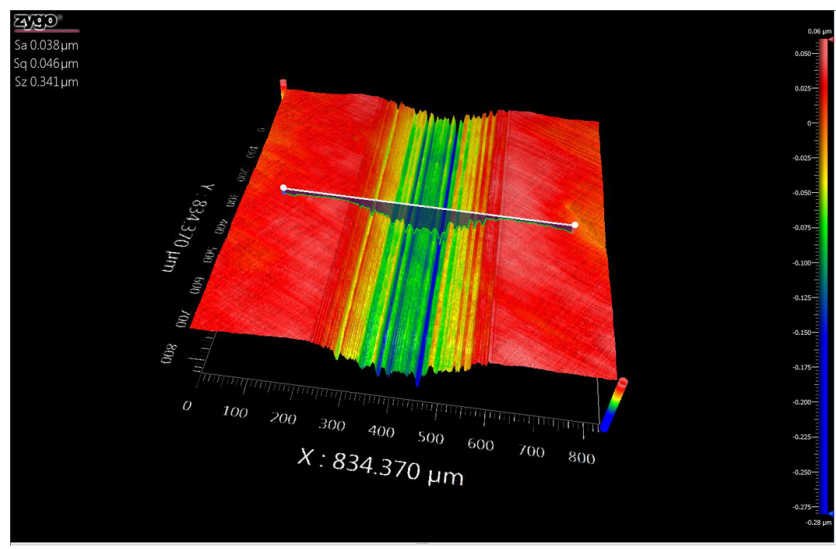

20150

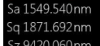

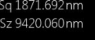

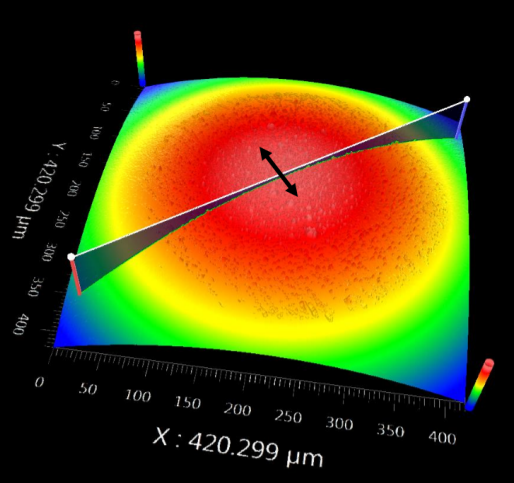

$\left(b_{1}\right)$ 

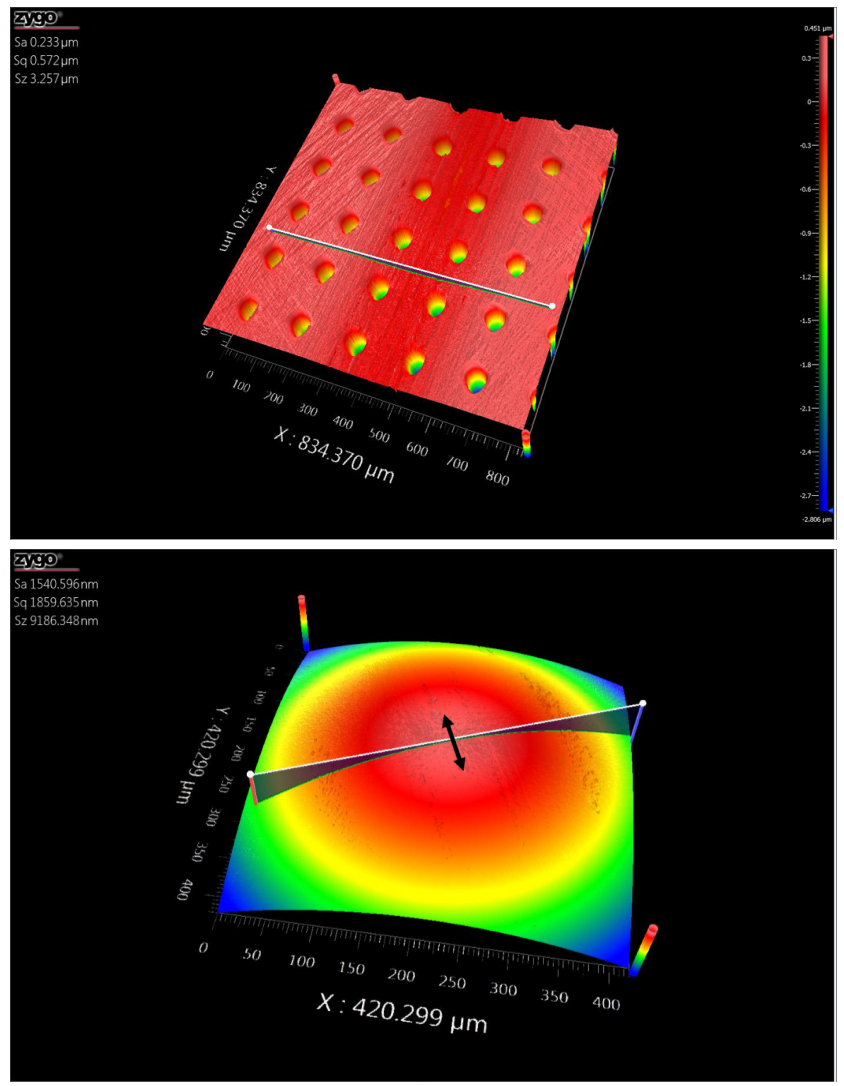

$\left(b_{2}\right)$

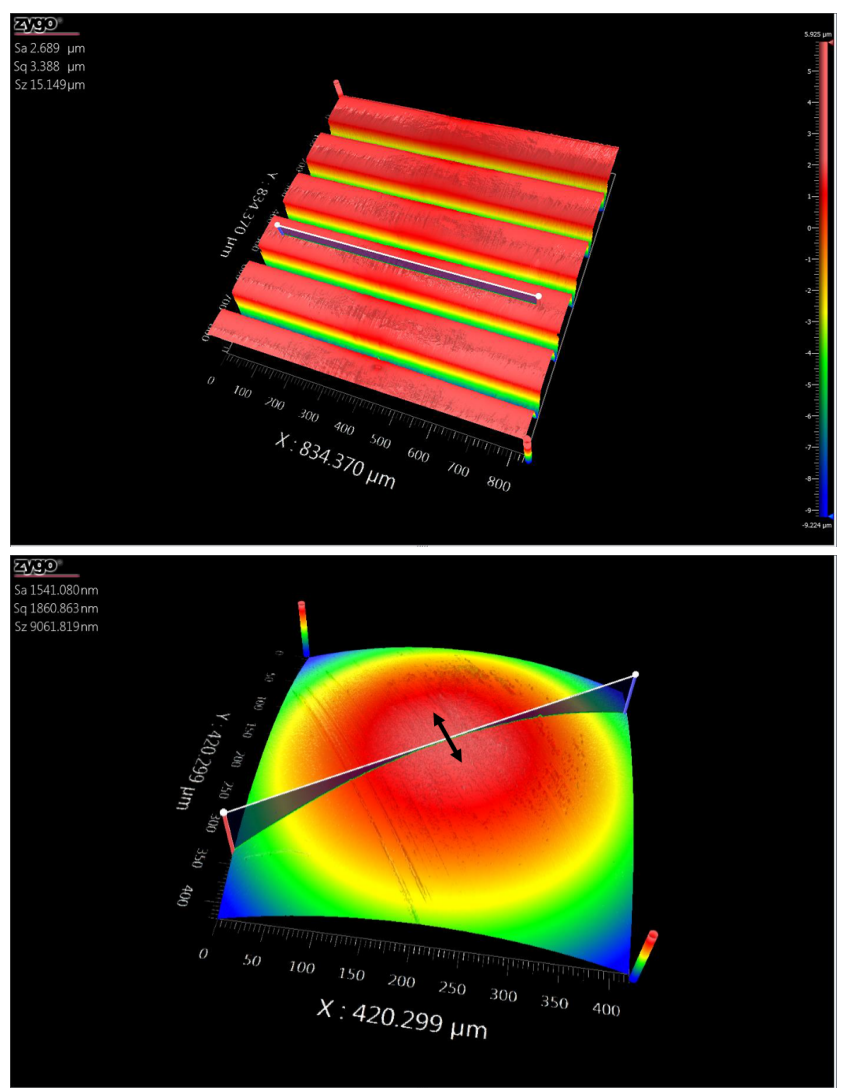

$\left(b_{3}\right)$ 

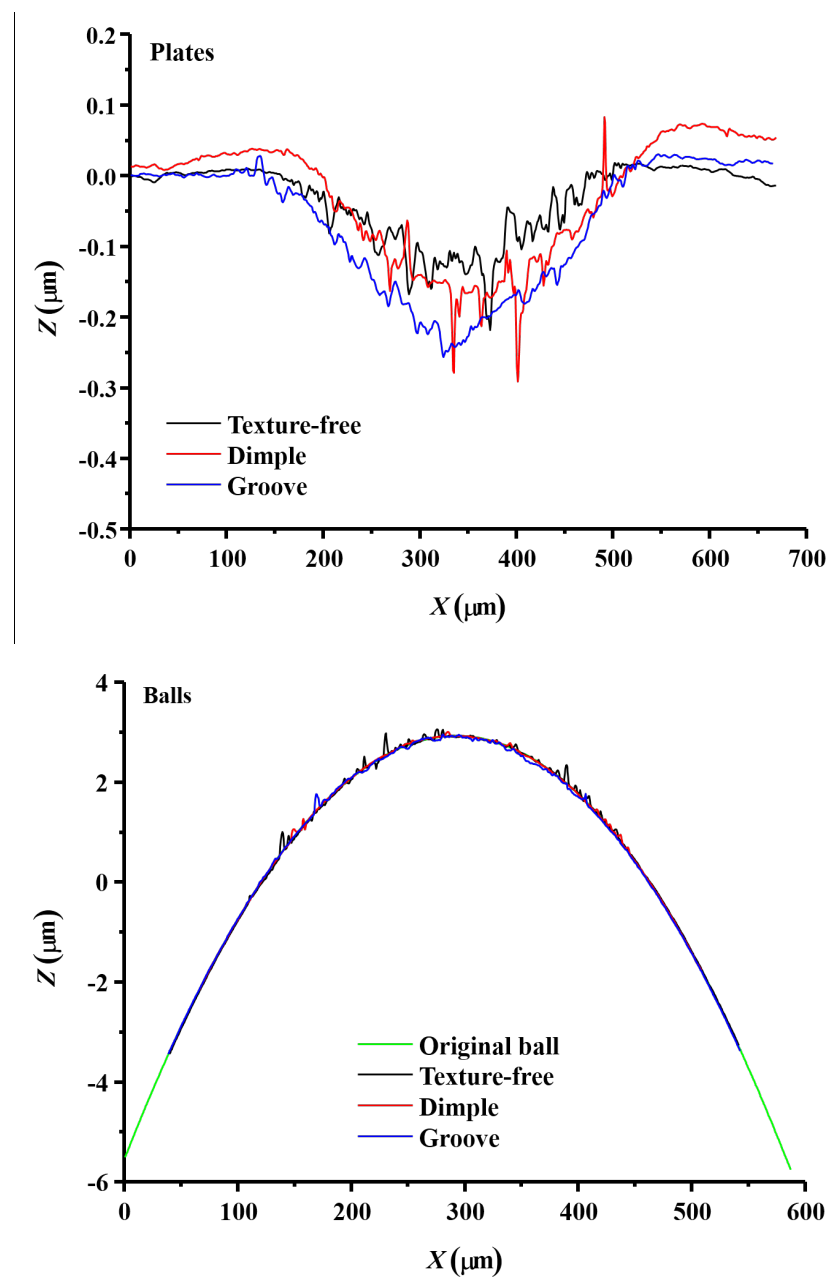

$\left(b_{4}\right)$

(b) base oil $+0.5 \mathrm{wt} \% \mathrm{MoDDP}$

Fig.18 Wear scar morphologies under flooded lubrication for texture-free $\left(a_{1}, b_{1}\right)$, dimple $\left(a_{2}, b_{2}\right)$ and groove $\left(a_{3}, b_{3}\right)$ textured surfaces and the balls, the black arrows depict the sliding direction

\subsection{Starved lubrication}

Optimized textured surfaces under flooded boundary lubrication conditions can also prolong the lifespan subject to starved boundary lubrication condition whether or not MoDDP was contained in the lubricant as shown in Fig.13 and Fig.14. It should be noted that the friction coefficient value of 0.1 remained constant throughout the testing until the lubrication failure if MoDDP was contained in the lubricant. However, this value was reduced to a lower friction coefficient in flooded lubricant conditions.

As described before, friction appears to drop because of the $\mathrm{MoS}_{2}$ nanosheets formed during the sliding process. However, some previous studies also show that the ability of organo-molybdenum friction modifier to reduce friction can be lost when they operate in oxidizing environments [4]. This has been attributed to oxidation of $\mathrm{MoS}_{2}$ sheets to high-friction 
$\mathrm{MoO}_{3}$ components or additives in the solution have been consumed due to their peroxide-decomposing antioxidant nature. In this experiment, the plate samples are covered with only a thin layer of lubricating oils, so the lubricant can not flow into the wear scar as in the flooded lubrication condition, which makes the material in wear scar oxidized easily. Furthermore, poor lubrication condition causes surface temperature to rise then leads to oxidize the boundary tribofilms.

Although the ability to reduce friction has been lost, the wear resistance of MoDDP tribofilm is still better. Fig.19 shows the SEM (Scanning Electron Microscope) micrographs of wear scar after lubrication failure of plate surfaces. Obvious pits can be seen in the wear scar when base oil was used as a lubricant, indicating that serious adhesive wear occurred. A small number of adhesive pits were formed when MoDDP was contained in the lubricant, however obvious plastic deformation can be seen within the wear scar as compared to when MoDDP was not included in the lubricant. This is because that the wear mainly occurred between the MoDDP tribofilm which were formed on the sliding surface, instead of a direct contact between metals. So MoDDP mainly provides antiwear performance rather than friction reduction characteristics subjected to starved lubrication.

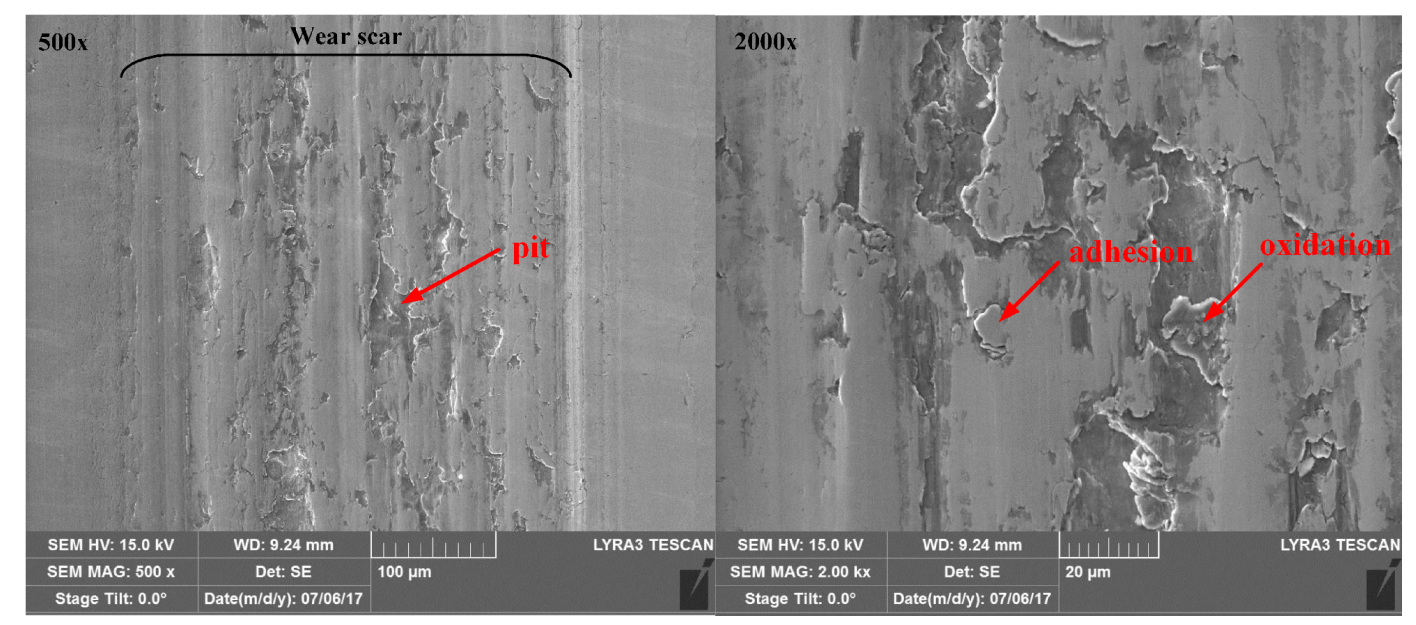

(a1) texture-free surface, base oil 


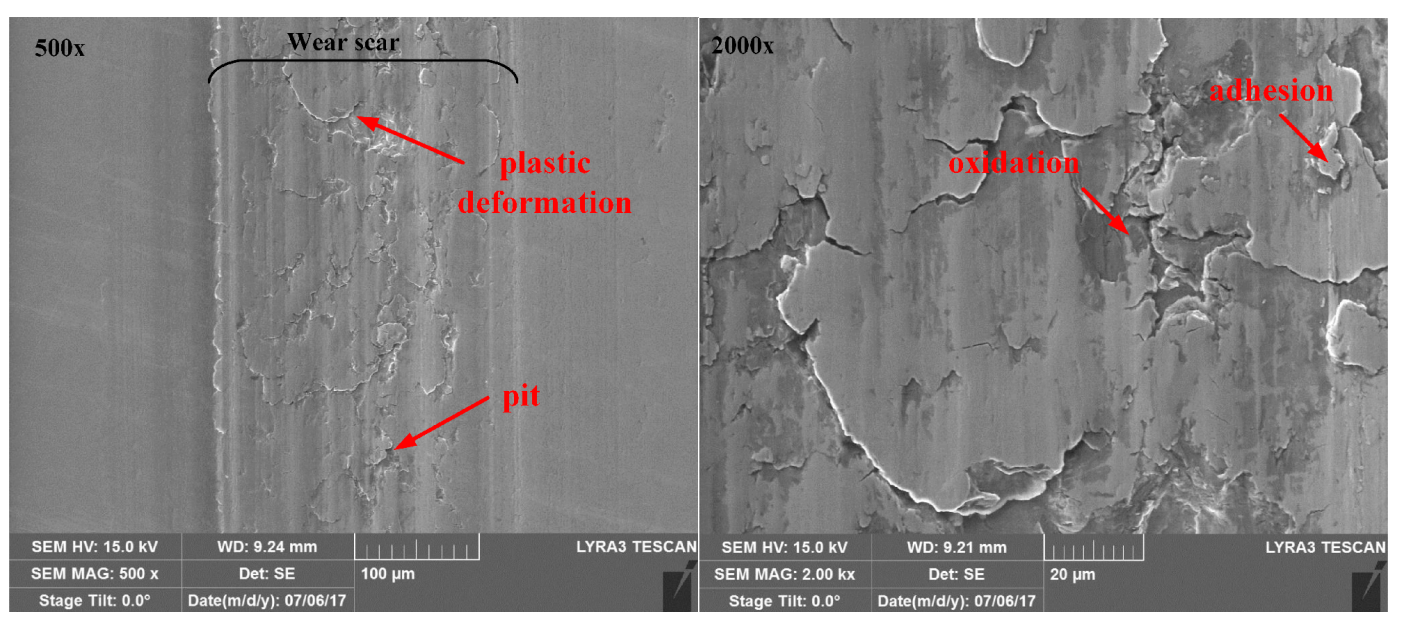

(b1) texture-free surface, base oil $+0.5 \mathrm{wt} \% \mathrm{MoDDP}$

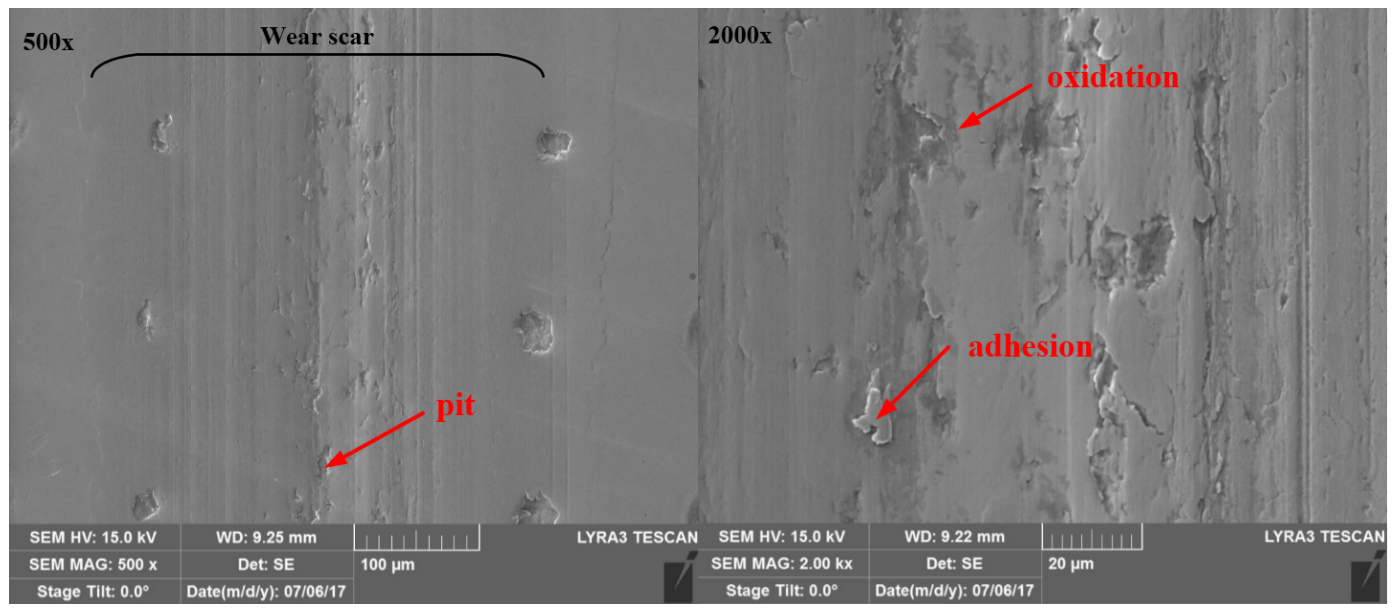

(a2) dimple textured surface, base oil

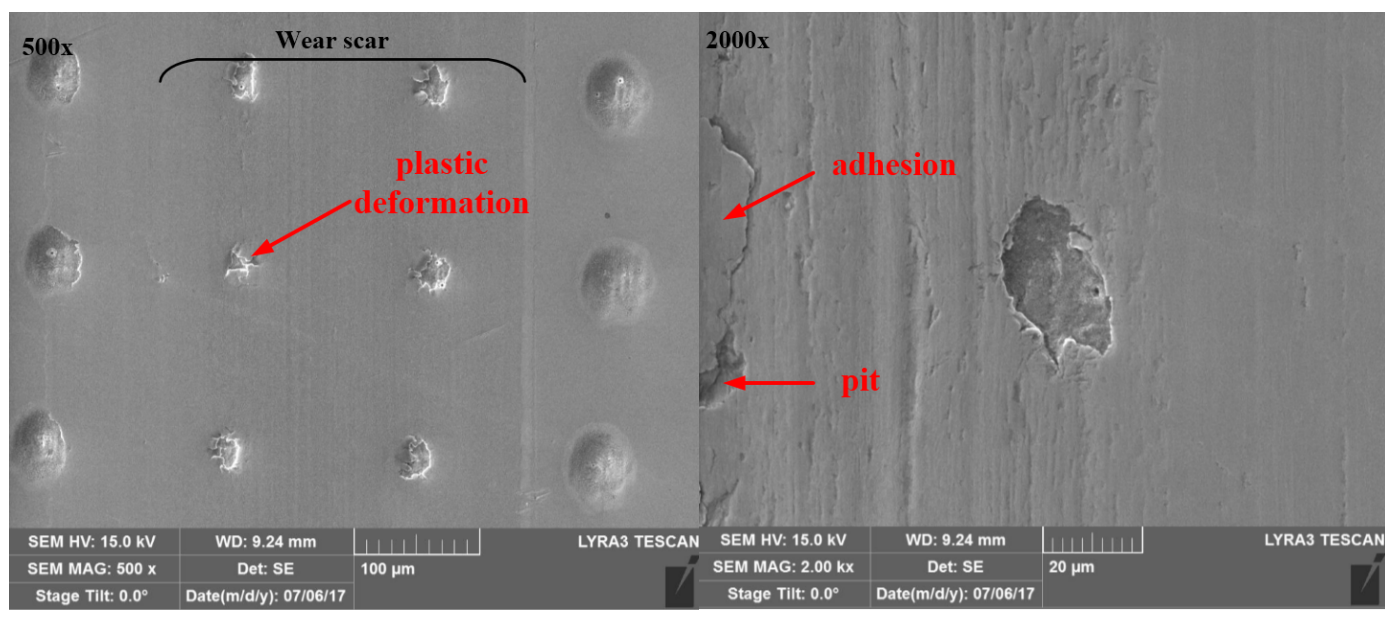

(b2) dimple textured surface, base oil $+0.5 \mathrm{wt} \% \mathrm{MoDDP}$ 


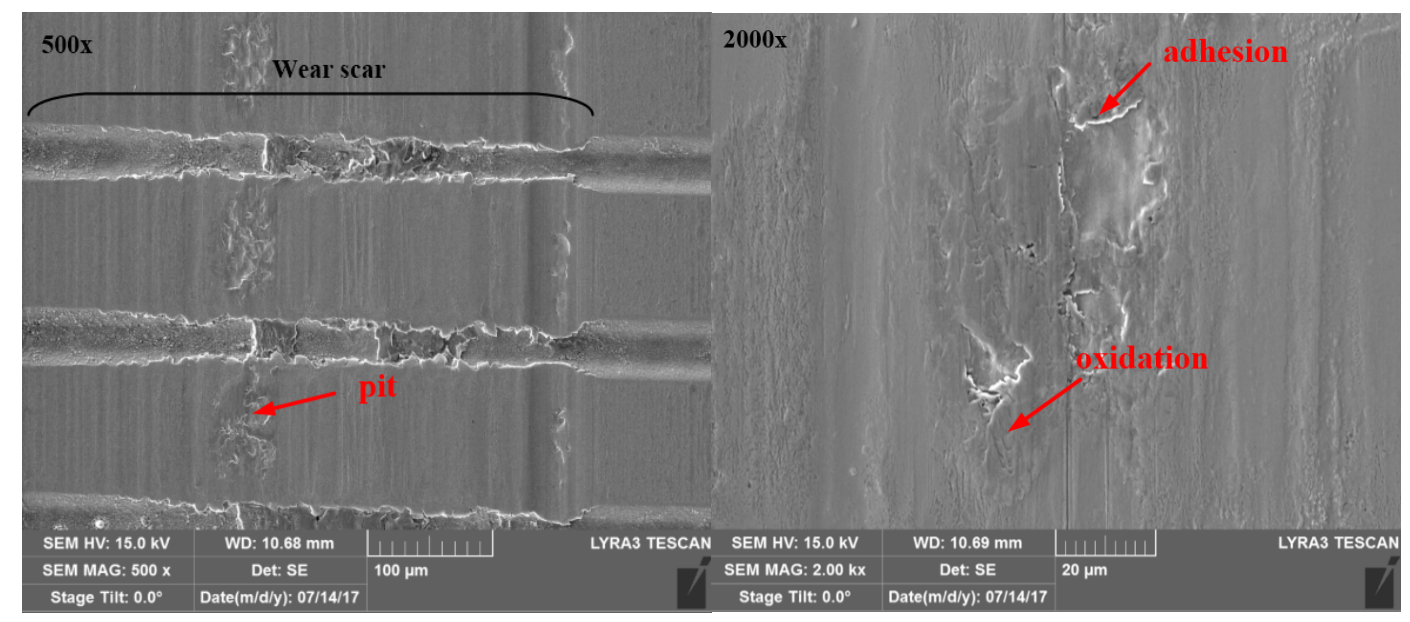

(a3) groove textured surface, base oil

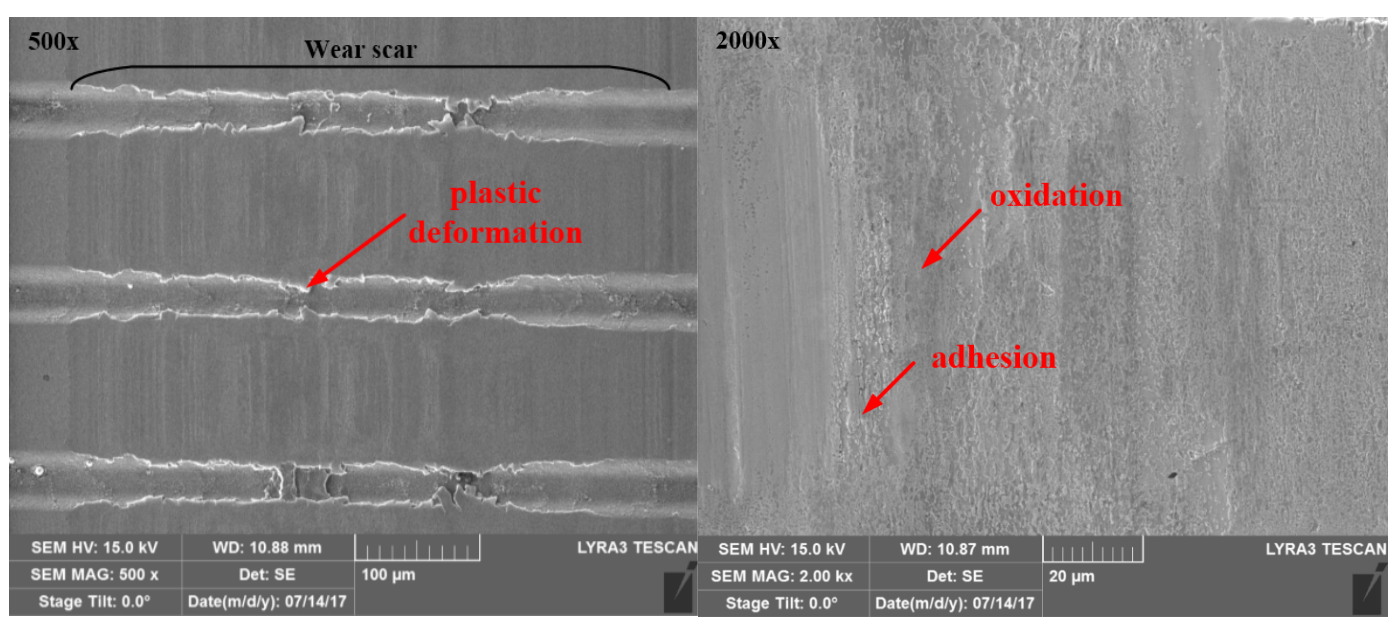

(b3) groove textured surface, base oil $+0.5 \mathrm{wt} \% \mathrm{MoDDP}$

Fig.19 SEM images of wear scar under starved lubrication

It is well known that when the lubricant maintains a complete boundary film the lifespan of friction pairs can be prolonged. In presence of MoDDP within the lubricant, the lifespan can be further prolonged when antiwear tribofilm is generated continuously. Fig.20 shows the photo of dimple-textured plate after lubrication failure. As shown in Fig.20, a very thin layer of oil film covered on the plate out of the wear scar, but there was almost no oils in the in wear scar. The lubricant in contact region was partly removed to the end of the stoke and two sides of the wear scar during the sliding process, reducing the volume of oil in contact area. Some research showed that the oils stored in textures extracted from the texture and supplied additional lubrication to the contacting region until the texture was completely empty [36]. In Fig.20, oils also could be seen extracted from the dimples near the edge of the wear scar. Fig.21 shows the schematic diagram of failure mechanism under starved lubrication. Only partial asperity peaks contact occurred in the initial stage because the boundary films are relatively thick. As the wear test continued, the contact 
area increased due to material wear but the lubricant could not flow into the contact area as compared to the flooded lubrication condition. This makes the boundary film thinner, or even part of the contact zone can not be lubricated. Furthermore, poor lubrication condition causes surface temperature rise, further making the boundary film rupture, resulting in lubrication failure. However, for the textured surface, the textures can store lubricant oil and solid wear particles to prevent or delay the rubbing surface from scuffing or severe wear. In the case of textured surfaces lubricant stored in the dimples or grooves plays a role of supplementary lubrication to the contacting surface. Due to starvation external lubricant can not still flow into the contact zone. Under this poorly lubricated conditions, existence of MoDDP additives in the lubricant can prolong the lifespan more obviously by generating antiwear tribofilms. Surface textures can promote the tribofilms formation as well as providing more MoDDP additives to the contact zone. So the lifespan of textured surface has been greatly enhanced when MoDDP is contained in the lubricant.

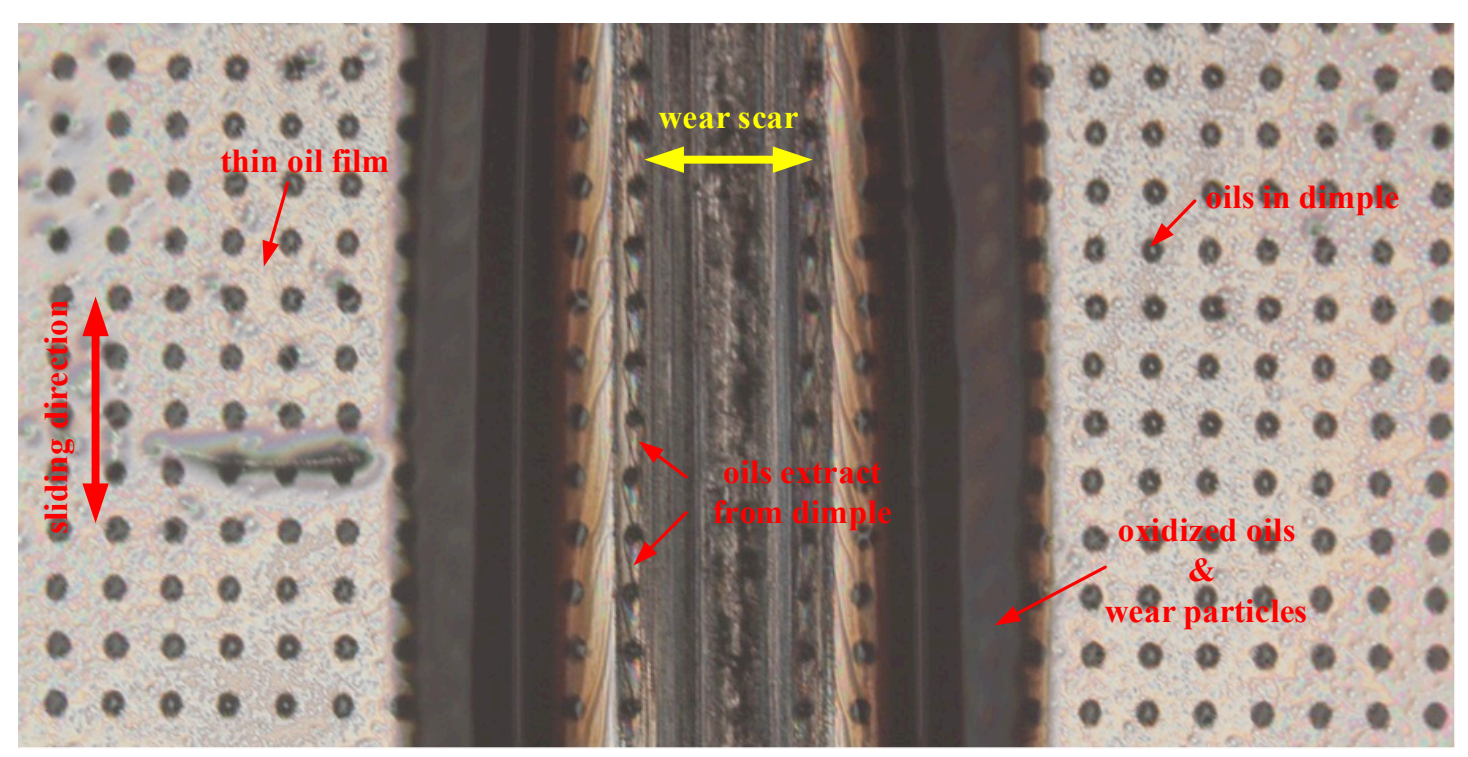

Fig.20 Photo of dimple-textured plate after lubrication failure subjected to starved lubrication 

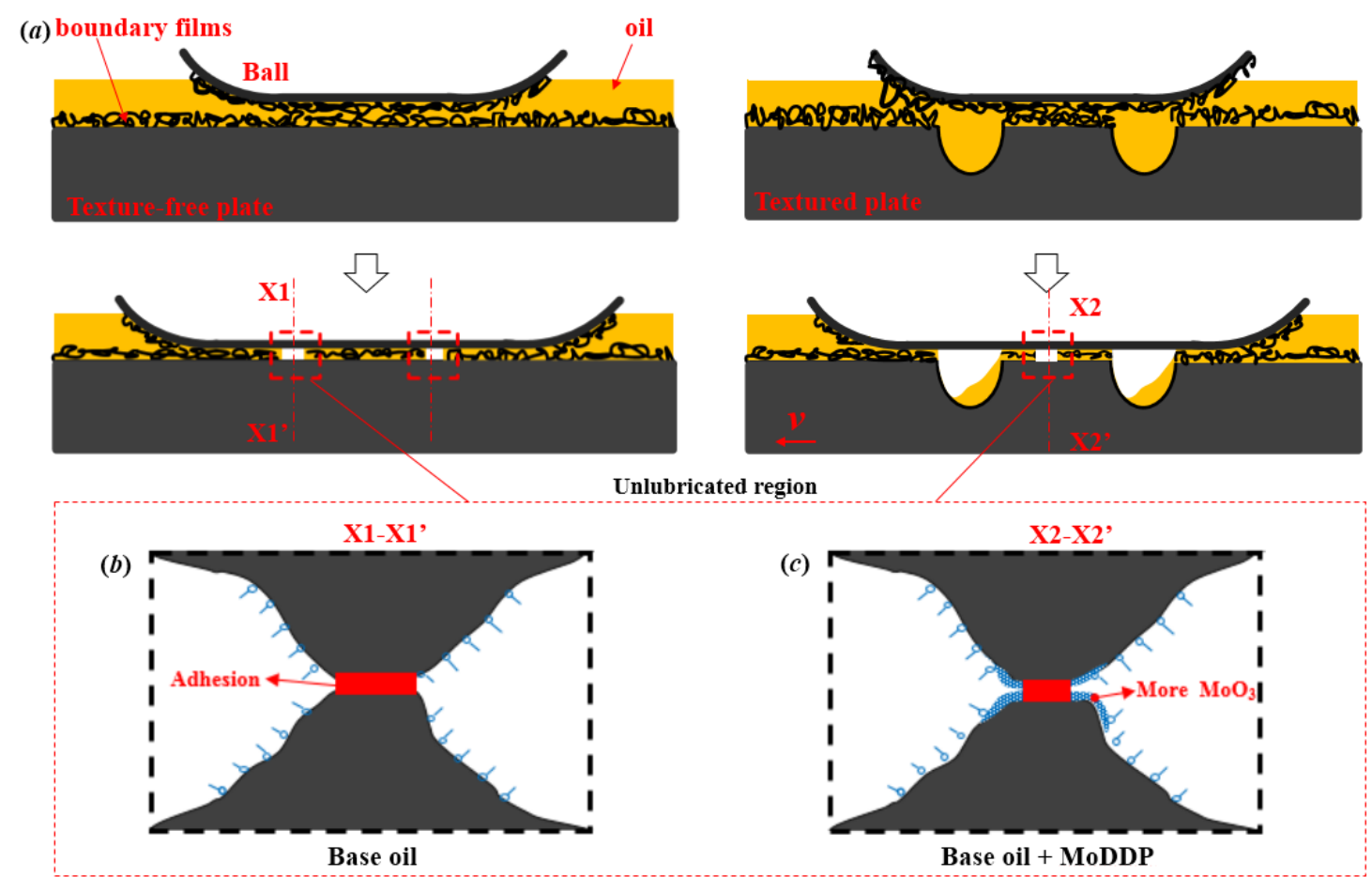

Fig.21 Failure mechanism under starved lubrication

(at asperity contact exploded cross-sectional views at X1X1' and X2X2' shown in Fig.21.(b) and

Fig.21.(c) )

In summary, the synergetic effects of surface texturing and MoDDP improve the lubrication performance significantly. When MoDDP was contained in the oil, the advantage of textured surface was more obvious. The synergetic effect between microscale surface texturing and MoDDP lubricant additive is emphasized. During this research two types of textured features, circular dimples and grooves, were investigated with or without the presence of MoDDP as a friction modifier. The sliding directions were kept constant for all of the experiments during the sliding process. Some research showed that the orientation effects are very important for the friction performance of textured surface [37]. So giving more in-depth research to study the orientation effects of circular dimples, grooves and other textures on synergetic effects of surface texturing and MoDDP additive is also a good research direction in the future. Meanwhile, the influence of operating conditions such as load, sliding speed and temperature were not within the scope of this research. It is suggested that this research maybe extended to other operating conditions and textured surfaces, for example, elliptical dimples, triangular dimples, grooves with different angles and alternative lubricant additives such as antiwear additives and antioxidant agents.

\section{Conclusions}


In this paper, the synergetic effects of surface textures and friction modifier MoDDP under flooded and starved boundary lubrication conditions were experimentally studied with the purpose of providing some insight into the application of surface textures in boundary lubrication as additives were contained in the lubricant. The friction coefficient and lifespan of texture-free surface and two types of most commonly used microscale texture surface, circular dimples and line grooves, were compared. The following conclusions can be drawn from the experimental results.

(1) Optimized surface textures and lubrication additive MoDDP are effective to improve the friction performance when either of these are used subjected to both flooded and starved boundary lubrication conditions.

(2) Under flooded boundary lubricant condition, the friction coefficient was more responsive to texture parameters when MoDDP was contained in the lubricant than only base oil was used. Meanwhile, the optimization parameters of circular-dimple and groove textures with MoDDP were different compared to base oil.

(3) Optimized textured surface subjected to flooded conditions can also prolong the lifespan of friction pair under starved oil lubrication condition whether or not MoDDP was contained in the lubricant. However, if MoDDP was contained in the lubricant, the advantage of textured surface was more obvious.

\section{Acknowledgments}

The authors would like to acknowledge the support of Shell Global Solutions (US) as well as the NSFC with the grant No. 51635009. 


\section{Reference}

[1] Bowden, F.P., Tabor, D.: The Friction and Lubrication of Solids. Oxiford: Clarendon Press (1950)

[2] Zhang, J., Meng, Y., Boundary lubrication by adsorption film, Friction 3, 115-147 (2015)

[3] Spikes, H.: Boundary lubrication and boundary films. Tribology Series 25, 331-346 (1993)

[4] Spikes, H.: Friction modifier additives. Tribology Letters 60, 5 (2015)

[5] Du, D. C., Kim, S. S., Suh, C. M., Chun, J. S., Moon, W. S., Kwon, W. S.: Effect of MoDDP on the antioxidative properties of ZnDDP in mineral oil. Lubrication Science 16, 183-193 (2004)

[6] Yamamoto, Y., Gondo, S.: Friction and wear characteristics of molybdenum dithiocarbamate and molybdenum dithiophosphate. Tribology Transactions 32, 251-257 (1989)

[7] Zhang, Z., Xue, Q., Zhang, J.: Synthesis, structure and lubricating properties of dialkyldithiophosphate-modified Mo- S compound nanoclusters. Wear 209, 8-12 (1997)

[8] Martin, J. M., Le Mogne, T., Grossiord, C., Palermo, T.: Tribochemistry of ZDDP and MoDDP chemisorbed films. Tribology Letters 2, 313-326 (1996).

[9] Xie, F., Hu, J., Yao, J., Zheng, F.: Antiwear synergism between organomolybdenum compounds and a ZnDDP. Lubrication Science 18, 1-5 (2006)

[10] Xie, F., Hu, J., Zheng, F., Ji, F., Yao, J.: Anti - wear performance of organomolybdenum compounds as lubricant additives. Lubrication Science 19, 81-85 (2007)

[11] Gondal, A. K., Sethuramiah, A., Prakash, B.: Studies on the tribological behaviour of two oil - soluble molybdenum compounds under reciprocating sliding conditions. Lubrication Science 5, 337-359 (1993)

[12] Etsion, I., Sher, E.: Improving fuel efficiency with laser surface textured piston rings. Tribology International 42, 542-547 (2009)

[13] Hao, L., Meng, Y., Chen, C. Experimental investigation on effects of surface texturing on lubrication of initial line contacts. Lubrication Science 26, 363-373 (2014)

[14] Etsion, I., Halperin, G.: A laser surface textured hydrostatic mechanical seal. Tribology Transactions 45, 430-434 (2002)

[15] Brizmer, V., Kligerman, Y., Etsion, I.: A laser surface textured parallel thrust bearing. Tribology Transactions 46, 397-403 (2003)

[16] Ryk, G., Kligerman, Y., Etsion, I.: Experimental investigation of laser surface texturing for reciprocating automotive components. Tribology Transactions 45, 444-449 (2002)

[17] Etsion, I.. State of the art in laser surface texturing. ASME Journal of Tribology 127, 248-253 (2005) 
[18] Wang, X., Kato, K., Adachi, K., Aizawa, K.: Loads carrying capacity map for the surface texture design of $\mathrm{SiC}$ thrust bearing sliding in water. Tribology International 36, 189-197 (2003)

[19] Zhang, J., Meng, Y.: Direct observation of cavitation phenomenon and hydrodynamic lubrication analysis of textured surfaces. Tribology letters 46, 147-158 (2012)

[20] Yan, D.S., Qu, N.S., Li, H.S., Wang, X.L.: Significance of dimple parameters on the friction of sliding surfaces investigated by orthogonal experiments. Tribology Transactions 53, 703-712 (2010)

[21] Wakuda, M., Yamauchi, Y., Kanzaki, S., Yasuda, Y.: Effect of surface texturing on friction reduction between ceramic and steel materials under lubricated sliding contact. Wear 254, 356-363 (2003).

[22] Pettersson, U., Jacobson, S.: Friction and wear properties of micro textured DLC coated surfaces in boundary lubricated sliding. Tribology letters 17, 553-559 (2004)

[23] Ajayi, O. O., Erck, R. A., Lorenzo-Martin, C., Fenske, G. R.: Frictional anisotropy under boundary lubrication: effect of surface texture. Wear 267, 1214-1219 (2009)

[24] Pettersson, U., Jacobson, S.: Influence of surface texture on boundary lubricated sliding contacts. Tribology International 36, 857-864 (2003)

[25] Cho, M., Choi, H. J. Optimization of surface texturing for contact between steel and ultrahigh molecular weight polyethylene under boundary lubrication. Tribology Letters 56, 409-422 (2014)

[26] Pettersson, U., Jacobson, S.: Textured surfaces in sliding boundary lubricated contacts mechanisms, possibilities and limitations. Tribology - Materials Surfaces \& Interfaces 1, 181-189 (2005)

[27] Shen, X., Tao, G.: Tribological behaviors of two micro textured surfaces generated by vibrating milling under boundary lubricated sliding. International Journal of Advanced Manufacturing Technology 79, 1995-2002 (2015)

[28] Menga, X., Zhanga, B., Jing, W., Qian, Z.: Experimental observation on the surface dimple variations in starved EHL of sliding steel-glass point contacts. Tribology International 105, 166-174 (2017)

[29] Svoboda, P., Koštál, D., Krupka, I.: The experimental study of transition between fully flooded and starved regime in EHL contact. Engineering Mechanics 20, 13-25 (2013)

[30] Jiang, L., He, Y., Luo, J. Chemical mechanical polishing of steel substrate using colloidal silica-based slurries. Applied Surface Science 330, 487-495 (2015)

[31] Wen, S., Huang, P.: The principle of tribology. 3rd Ed. Beijing: Press of Tsinghua University (2009) 
[32] Graham, J., Spikes, H., Korcek, S.: The friction reducing properties of molybdenum dialkyldithiocarbamate additives: part I - factors influencing friction reduction. Tribology Transactions 44, 626-636 (2001)

[33] Wang, X., Wang, J., Zhang, B., Huang, W.: Design principles for the area density of dimple patterns. ARCHIVE Proceedings of the Institution of Mechanical Engineers Part J: Journal of Engineering Tribology 229, 538-546 (2014)

[34] Gong, Z. Q., Komvopoulos, K.: Mechanical and thermomechanical elastic-plastic contact analysis of layered media with patterned surfaces. Journal of Tribology 126, 9-17 (2004)

[35] Zhao, J., Sadeghi, F., \& Nixon, H. M.: A finite element analysis of surface pocket effects in hertzian line contact. Journal of Tribology 122, 47-54 (2000)

[36] Wang, P.C., Sadeghi, F., Wereley, S.T., Jr, R.G.R., \& Rowan, S.: Experimental investigation of lubricant extraction from a micropocket. Tribology Transactions 54, 404-416 (2011).

[37] Yuan, S., Huang, W., \& Wang, X.: Orientation effects of micro-grooves on sliding surfaces. Tribology International 44, 1047-1054 (2011) 


\section{Figure captions}

Fig.1 Schematic of test rig

Fig.2 Lubricant supply under starved lubrication

Fig.3 Schematic diagram of lubrication conditions

Fig.4 Topography profiles of textured surface

Fig. 5 The molecular formula of MoDDP $(\mathrm{R}=$ alkyl group $)$

Fig.6 3D interferometry images and profiles of the ball and plate

Fig.7 Influence of dimple depth $(L=150 \mu \mathrm{m})$

Fig. 8 The influence of dimple center distance $(h=2.5 \mu \mathrm{m})$

Fig.9 The influence of concentration $(h=2.5 \mu \mathrm{m}, L=150 \mu \mathrm{m})$

Fig.10 The influence of groove depth $(L=150 \mu \mathrm{m})$

Fig.11 The influence of groove center distance $(\mathrm{h}=10 \mu \mathrm{m})$

Fig. 12 Influence of concentration $(\mathrm{h}=10 \mu \mathrm{m}, \mathrm{L}=150 \mu \mathrm{m})$

Fig.13 Friction performance under starved lubrication conditions (dimple)

Fig.14 Friction performance under starved lubrication conditions (groove)

Fig. 15 Induced period of dimple textured surfaces with different depth ( base oil $+0.5 \mathrm{wt} \%$ MoDDP, $\mathrm{L}=150 \mu \mathrm{m})$

Fig.16 Boundary film structures

Fig. 17 Contact pressure distribution

Fig.18 Wear scar morphologies under flooded lubrication for texture-free (a1, b1), dimple (a2, b2) and groove $(\mathrm{a} 3, \mathrm{~b} 3)$ textured surfaces and the balls, the black arrows depict the sliding direction Fig.19 SEM images of wear scar under starved lubrication (texture-free)

Fig.20 Photo of dimple-textured plate after lubrication failure subjected to starved lubrication

Fig.21 Failure mechanism under starved lubrication 